\title{
Null mutation of $D l x-2$ results in abnormal morphogenesis of proximal first and second branchial arch derivatives and abnormal differentiation in the forebrain
}

\author{
Mengsheng Qiu,, Alessandro Bulfone, ${ }^{1}$ Salvador Martinez, ${ }^{2}$ Juanito J. Meneses, ${ }^{3}$ Kenji Shimamura, ${ }^{1}$ \\ Roger A. Pedersen, ${ }^{3}$ and John L.R. Rubenstein ${ }^{1,4}$ \\ ${ }^{1}$ Nina Ireland Laboratory of Developmental Neurobiology, Center for Neurobiology and Psychiatry, Department \\ of Psychiatry and Programs in Neuroscience and Developmental Biology, University of California at San Francisco, \\ San Francisco, California, 94143-0984 USA; ${ }^{2}$ Department of Anatomy, Faculty of Medicine, University of Murcia, Murcia, \\ Spain $30100 ;{ }^{3}$ Laboratory of Radiobiology and Environmental Health, University of California at San Francisco, \\ San Francisco, California USA
}

Genetic analysis of the development and evolution of the vertebrate head is at a primitive stage. Many homeo box genes, including the Distal-less family, are potential regulators of head development. To determine the function of $D l x-2$, we generated a null mutation in mice using gene targeting. In homozygous mutants, differentiation within the forebrain is abnormal and the fate of a subset of cranial neural crest cells is respecified. The latter causes abnormal morphogenesis of the skeletal elements derived from the proximal parts of the first and second branchial arches. We hypothesize that the affected skull bones from the first arch have undergone a transformation into structures similar to those found in reptiles. These results show that $D l x-2$ controls development of the branchial arches and the forebrain and suggests its role in craniofacial evolution.

[Key Words: Homeo box genes; mouse development; Dlx-2; vertebrate head; branchial arch; forebrain]

Received June 20, 1995; revised version accepted August 25, 1995.

The vertebrate head is a modular structure built in part from segmental neuroectodermal units (Lumsden and Keynes 1989; Rubenstein et al. 1994). The head differs from the body in two major ways. First, much of the brain is overtly segmented (Lumsden et al. 1991; Rubenstein et al. 1994), whereas the spinal cord of higher vertebrates does not exhibit intrinsic segmentation (Stern et al. 1991). Second, neural crest from the brain [cranial neural crest $(\mathrm{CNC})]$ can differentiate into many more types of tissues than the spinal neural crest (Noden 1988; Langille and Hall 1993; LeDouarin et al. 1993). The neural crest of the head and the body form the peripheral nervous system (PNS) (Bronner-Fraser and Fraser 1989; LeDouarin et al. 1993), whereas only the CNC contributes to skeleton, muscles, and blood vessels (Baroffio et al. 1991). Thus, the CNC is involved in major aspects of craniofacial development, and many of the morphological features that characterize the vertebrate head are patterned by the CNC. The developmental program of the $\mathrm{CNC}$ is determined while these cells are still in the brain (Noden 1983).

\footnotetext{
${ }^{4}$ Corresponding author.
}

There are three major transverse subdivisions of the brain: the hindbrain, midbrain, and forebrain. The anterior part of the embryonic hindbrain is subdivided into seven segments, the rhombomeres (Lumsden et al. 1991). CNC from pairs of rhombomeres generally migrate ventrally, some associating with ectodermal placodes to give rise to the cranial sensory ganglia; others migrate more ventrally to become the mesenchyme of the branchial arches, where they form skeletal, muscular, and vascular structures (Lumsden et al. 1991; Sechrist et al. 1993).

There is increasing evidence that many aspects of hindbrain and branchial arch development are controlled by the Hox family of homeo box genes. Although Hox genes from paralogue groups 1,2, 3, and 4 are expressed in the rhombencephalon (Krumlauf 1993), mutations in some affect development of the hindbrain (Hox-a1) (Carpenter et al. 1993; Dollé et al. 1993) and mutations in others (Hox-a2 and Hox-a3) appear not to disrupt the CNS (Chisaka and Capecchi 1991; Gendron-Maguire et al. 1993; Rijii et al. 1993). Mutations in all of these Hox genes do affect development of the CNC, although they influence different subsets of these cells. For instance, 
loss of Hox-a1 function mainly affects neurogenic CNC (Lufkin et al. 1991; Chisaka et al. 1992), and loss of Hoxa2 primarily alters mesenchymal CNC-derived tissues (Gendron-Maguire et al. 1993; Rijii et al. 1993). The Hox genes are not expressed in regions rostral to rhombomere 2 , which is near the hindbrain/midbrain junction and are not expressed in the first branchial arch; therefore, other genes must control development of the mesencephalon, prosencephalon, and craniofacial regions rostral of the second branchial arch.

The midbrain (mesencephalon) is the second major brain subdivision. CNC derived from the midbrain and rhombomeres 1, 2, and 3 form the trigeminal ganglion and populate the first branchial arch (Lumsden et al. 1991). There is also evidence that mesencephalic CNC's contribute to the development of the eye (Matsuo et al. 1993). Several types of homeo box genes are expressed in the midbrain, including vertebrate homologs of the engrailed (En-1 and En-2) (Davis and Joyner 1988), orthodentical (Otx-1 and OtX-2), and empty spiracle (Emx-2) genes (Simeone et al. 1992). Mutations in the En-1 and En-2 genes disrupt development of the midbrain and rostral rhombencephalon (Joyner et al. 1991; Wurst et al. 1994), but no phenotype has been reported in the branchial arches. There are other mouse homeo box genes that are expressed in the CNC that populates the first branchial arch. These include five distal-less genes $\left(D l_{X}\right.$ 1, Dlx-2, Dlx-3, Dlx-5, and Dlx-6) (Porteus et al. 1991; Price et al. 1991; Robinson et al. 1991; Simeone et al. 1994; Robinson and Mahon 1994) as well as the MsX-1 and MsX-2 (MacKenzie et al. 1991), MHox (Cserjesi et al. 1992), and Gsc (Gaunt et al. 1993) genes. Mutation of MsX-1 and MHox disrupts development of CNC-derived tissues of the first arch (Satokata and Maas 1994; Martin et al. 1995).

The forebrain is the rostral-most subdivision of the central nervous system (CNS). There are at least 25 homeo box genes that are expressed in regionally restricted patterns in the forebrain, whose boundaries are consistent with a prosencephalic segmental organization (Rubenstein and Puelles 1994). Among them are the members of the Dlx,Emx, and Otx families that are related to genes expressed in segmental patterns in the embryonic fly head.

Here we describe the functional analysis of the murine $D l x-2$ homeo box gene. Dlx-2 is primarily expressed in the neurogenic and chondrogenic $\mathrm{CNC}$ and in the forebrain. Loss of $D l x-2$ function disrupts development of subsets of these cells. In the forebrain, loss of $D l x-2$ function does not clearly alter regional specification but does reveal that $D l x-2$ controls development of at least one cell type, the periglomerular cells of the olfactory bulb. Derivatives of the proximal region of the first branchial arch are affected most severely by the mutation, and a subset of the affected bones have morphologies similar to those found in reptiles. Thus, $D l x-2$ regulates regional specification of the CNC that populates the maxillary branch of the first arch, and loss of Dlx-2 function appears to transform several skeletal elements toward more primitive evolutionary forms.

\section{Results}

Generation of mice with a deletion in the Dlx-2 gene

To determine the role of the Dlx-2 gene, we used homologous recombination in embryonic stem (ES) cells (Thomas and Capecchi 1987; Joyner 1994) to generate a strain of mice that has a deletion in Dlx-2. A schematic of the genomic organization of Dlx-2 is shown in Figure $1 \mathrm{~A}$, which is based on nucleotide sequence analysis of Dlx-2 (T. McGuinness, M.H. Porteus, and J.L. Rubenstein, unpubl.). Using this information, we constructed a gene replacement vector designed to make an $\sim 5$-kb deletion in Dlx-2 (Fig. 1A). This deletion removes the sequence encoding 199 of 331 of the DLX-2 amino acids (including the homeo domain).

The gene replacement vector was electroporated into ES cells, and we analyzed 250 independent clones by Southern blot analysis (Fig. 1B) with a probe that comes from the region flanking the $5^{\prime}$ end of the $D l x-2$ sequences in the replacement vector (probe A in Fig. 1A); Eleven ES clones were identified that had the predicted deletion in one Dlx-2 allele and were further confirmed with another flanking probe (probe B, Fig. 1A; data not shown). Four clones were injected into blastocysts to produce chimeric mice. Each of these produced highly chimeric offspring that passed the mutant allele through their germ line (Fig. 1B). Mice heterozygous for the DlX$2-D 5 / n e o$ are indistinguishable from wild-type littermates. Heterozygotes were mated to generate mice that were homozygous for the $D l x-2-D 5 /$ neo allele.

To verify that the wild-type $\sim 2.6-\mathrm{kb}$ Dlx-2 transcript is missing in the mutant mice, the RNA was probed with a DNA fragment (probe 2, Fig. 1A) from a portion of the $D l x-2$ gene that had been deleted. Figure $1 \mathrm{C}$ shows that this probe detects the expected $\sim 2.6-\mathrm{kb}$ transcript in wild-type but not in Dlx-2-D5/neo homozygotes. In addition, immunohistochemistry with anti-DLX-2 antibodies showed no staining in Dlx-2-D5/neo homozygotes (data not shown).

\section{Dlx-2-D5/neo homozygotes die the day of birth and have gross craniofacial and gastrointestinal abnormalities}

Dlx-2-D5/neo homozygotes from four independent cell lines had indistinguishable phenotypes in both hybrid $(129 \times \mathrm{CD} 1)$ and inbred (129) genetic backgrounds. We performed a detailed phenotypic characterization on the progeny of two founder ES cell lines (39 and 73).

Genotype analysis of the offspring from heterozygote crosses showed Mendelian segregation ratios in prenatal and newborn mice $(102: 204: 113,+/+,+/-,-/-)$. This demonstrates that Dlx-2-D5/neo homozygotes do not die in large numbers in utero. However, all Dlx-2$D 5 /$ neo homozygotes die within $24 \mathrm{hr}$ after birth. The newborn Dlx-2-D5/neo homozygotes had decreased spontaneous movements, gasping respiration, and cyanotic skin. They do not nurse, and they accumulate air in their stomachs and intestines after birth (Fig. 2F), and gradually weaken and die. 
The massive distention of their proximal gastrointestinal tract could be caused by a structural obstruction, an abnormality in gut motility, or the swallowing of excessive air. Whereas we found no evidence for a structural obstruction, we observed that the small intestine in the newborn (PO) homozygotes showed much less peristalsis, implying a defect in the enteric neuromuscular system. $D l x-1$ and $D l x-2$ are expressed in the enteric nervous system during midgestation (Fig. 2C,D) $(D I x-2$ is expressed in intestinal enteric neurons, although this is not shown clearly in Fig. 2D). In Dlx-2-D5/neo homozygotes at embryonic day 14.5 (E14.5), expression of Dlx-1 is lacking in the gut (Fig. 2E), implying that the cells normally expressing $D l_{X}-1$ were either missing or not properly differentiated.

The external anatomy of $D l x-2-D 5 /$ neo homozygotes showed that $\sim 80 \%$ of the $D 1 x-2-D 5 /$ neo homozygotes had a cleft secondary palate (Fig. 3B-D). A study of the morphology of the skull, described in the next section, revealed extensive abnormalities that may cause the cleft palate.

\section{The Dlx-2 mutant mice exhibit abnormal craniofacial bones}

Previously, we reported that $D l_{x}-2$ is expressed in CNC cells, which probably originate from the hindbrain and possibly the mesencephalon, and migrate into the branchial arch region (Bulfone et al. 1993a). Dlx-2-expressing CNC cells are found in the developing craniofacial ganglia (neurogenic CNC) and mesenchyme (mesenchymal CNC). Mesenchymal CNC cells contribute to several tissues, including craniofacial bones, cartilage, and teeth (Noden 1988; Langille et al. 1993; LeDouarin et al. 1993). We used the alizarin red $S$ and alcian blue method (McLeod 1980) to differentially stain bone (red) and cartilage (blue) in the skeletons of prenatal and newborn (P0) pups. Comparison of $\sim 60$ skeletons revealed no morphological differences between wild type and heterozygotes. However, all of the mutant homozygotes have multiple defects in a subset of the craniofacial bones and cartilages (Figs. 3-5).

The structure of several bones and cartilages is consistently altered, although detailed aspects of their shapes vary from individual to individual. In the following section, we describe the alterations in the skulls of animals ranging in age from E14.5 to P0.

Components of the skull are generally categorized into three groups that have distinct embryological and/or evolutionary relationships: the neurocranium, the splanchnocranium, and the dermatocranium. The neurocranium and splanchnocranium form from cartilaginous intermediates; therefore, these bones are classified as the chondrocranium. Dermatocranial bones, also called membrane bone, ossify in a noncartilaginous mesenchyme. The neurocranium forms the base of the skull and the capsules that surround the sense organs (eyes, ears, and olfactory epithelium), whereas the splanchnocranium originated as the skeleton of the branchial arches (Barghusen and Hopson 1979). Dermatocranial bones encase the neuro- and splanchnocranial structures, and form the roof of the skull (Couly et al. 1993). Splanchnocranial and dermatocranial bones are derived from CNC, whereas only some bones of the neurocranium are CNC derived (Couly et al. 1993). During vertebrate evolution, skull bones have been altered that create species-specific skeletal changes. The CNC-derived bones show dramatic morphological variations between species. For instance, components of the splanchnocranium produce mammalian-specific structures: the middle ear bones (incus, malleus, and stapes) and the alisphenoid (which forms part of lateral skull wall). Loss of Dlx-2 function has a profound effect on the development of many of these CNC-derived structures. We have subdivided the description of our analysis of the Dlx-2 mutants into alterations of these classes of bones and cartilage, which are summarized in Table 1.

Neurocranial analysis Studies in birds have demonstrated that rostral to the end of the notochord (prechordally), the neurocranium is formed from CNC, whereas parachordal neurocranial structures are of mesodermal origin (Couly et al. 1993). Extrapolation of the avian results to the mouse suggests that the most rostral mesodermal component of the murine neurocranium would be the basisphenoid. Lateral to the basisphenoid are CNC-derived structures. In PO wild-type and heterozygote animals, the basisphenoid is ossified and connected at its lateral aspects with cartilaginous components of the alisphenoid (Fig. 3E), and is connected with other components of the neurocranium by cartilaginous bridges; the presphenoid is rostral, and the basioccipital is caudal to the basisphenoid (Fig. 3C,E). From the caudal part of these processes arises the alicochlear commissure (ACC) that contacts the otic capsule. The primordia of these structures can clearly be seen at E14.5 (Fig. 3A,B). Lateral to the basisphenoid is the knob-like basitrabecular process (BT). Articulating with the BT is the ala temporalis (AT) and the ACC. The AT contributes to part of the alisphenoid (Presley 1981). The lateral aspects of the basisphenoid are altered in the mutant mice (Figs. $3 B, D, F, G, H, J, L$ and $5 B$; see legend for details).

Splanchnocranial alterations The mutant P0 animals have abnormalities in bones/cartilages derived from the proximal (dorsal) parts of the first and second arch (see Table 1). The first arch has two major subdivisions: the maxillary (considered as dorsal or proximal) and the mandibular (considered as ventral or distal). It is generally believed that maxillary mesenchyme gives rise to the pterygoquadrate cartilage of lower vertebrates (Barghusen et al. 1979; de Beer 1985), which is homologous to several separate mammalian bones (part of the alisphenoid and incus) (Barghusen et al. 1979; de Beer 1985). The mandibular mesenchyme gives rise to Meckel's cartilage, whose dorsal region forms the malleus in mammals.

In the first arch, only the maxillary derivatives are abnormal in the mutant mice, which can clearly be seen at E14.5, E16.5, and P0 (Fig. 3). The major abnormalities 
Qiu et al.

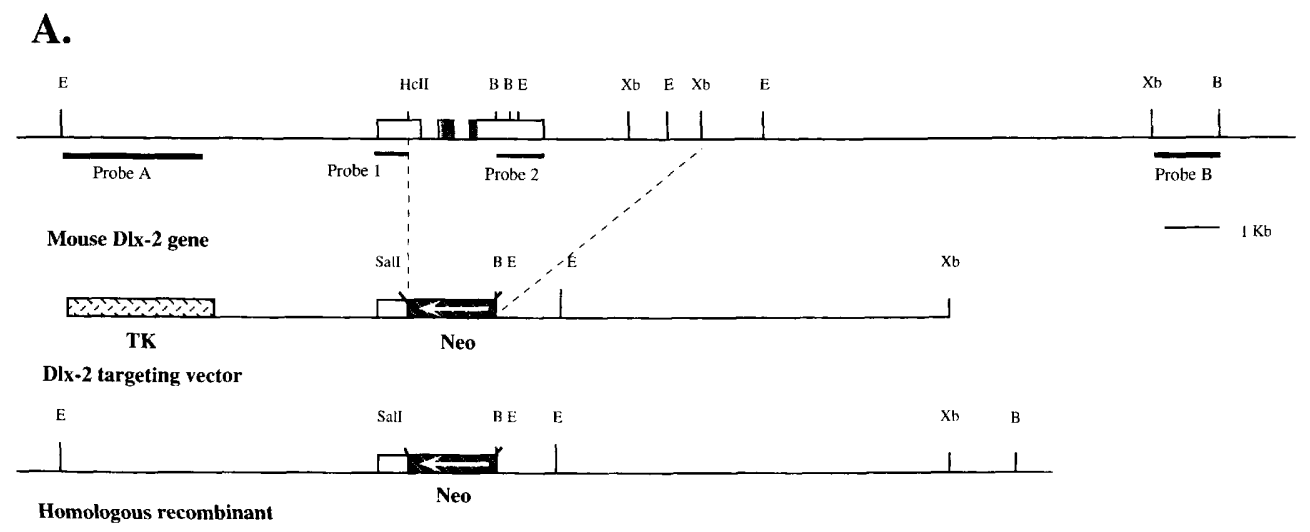

Figure 1. (A) Structure of the Dlx-2 gene and targeting vector. (Top line) Diagram of the genomic organization of Dlx-2 on mouse chromosome 2 and gene replacement strategies for targeting $D l x-2$. Open boxes represents exons; the blackened regions of those boxes correspond to the homeo box in exons two and three. Probes A and B were the flanking probes used for genotyping the mutant ES cells and mutant mice. Probes 1 and 2 were isolated from a Dlx-2 cDNA clone; probe 1 corresponds to the part of exon 1 that is not deleted in the mutant allele, and probe 2 corresponds to exon 3 that is deleted in the mutant allele. (Middle line) Diagram of the Dlx-2 targeting vector, showing the PGKneo cassette (solid box with hatch marks; the white arrow shows the direction of transcription off of the $P G K$ promoter) flanked by fragments ( 4.5 and 8.5 $\mathrm{kb}$ ) from the $D I x-2$ gene. The extent of the deletion in Dlx-2 is indicated by the broken lines that connect the top and middle diagrams. The PGKtk cassette (TK) is shown to B.

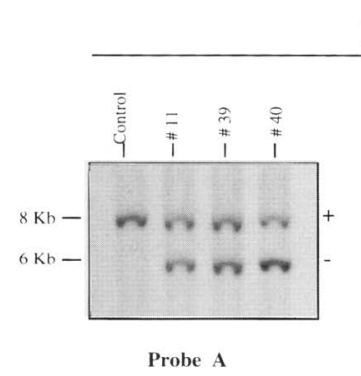

C.

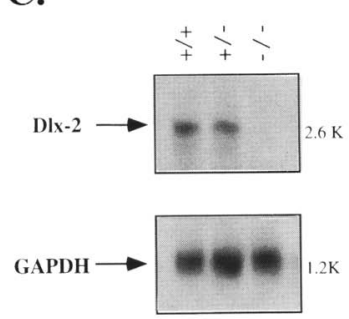
the left of the 5 Dlx-2 fragment. (Bottom line) Diagram of the structure of the mutant Dlx-2 allele $(D l x-2-D 5 / n e o)$. Abbreviations: (B) BamHI; (E) EcoRI; (HcII) HincII; (Xb) XbaI. (B) Genotyping by Southern analysis of ES clones and $\mathrm{F}_{2}$ animals. Genomic DNA isolated from ES cells \{clones $11,39,40$ ) or mouse tails was either digested with EcoRI plus Sall and hybridized with probe A, or digested with $B a m H I$ and hybridized with probe B (probes A and B are defined above). $|+|$ The wild-type allele; $(-\mid$ the mutant allele. $(C)$ Northern analysis of $D l x-2$ expression in the mutant animals. Two micrograms of poly $(A)^{+}$RNA from an entire E14.5 embryo, isolated from wild-type $(+1+1$, heterozygote $(+1-1$, and homozygote $(-1-)$ animals, was hybridized with a probe from the deleted region (probe 2 in $A$ ). The same membrane was then rehybridized with GAPDH as an internal control for the quantity of RNA. The RNA expression level in heterozygote is approximately half of that in wild type; no expression is found in the homozygote.

include a deletion in most of the alisphenoid, abnormal morphology of the incus, and the formation of a novel ectopic cartilage (see legend to Fig. 3 for details). The shape, position, and articulations of the ectopic cartilage led us to hypothesize that it is homologous to the pterygoquadrate, the splanchnocranial element of the maxillary arch of nonmammalian vertebrates.

Dorsal (proximal) second arch bones/cartilages are also abnormal, whereas ventral structures are unaffected. The second arch forms Reichert's cartilage, which dorsally gives rise to the stapes and the styloid process, and ventrally forms part of the hyoid bone (Barghusen et al. 1979; de Beer 1985). In mutant P0 animals, the stapes lacks a central hole (Figs. $4 \mathrm{H}$ and 5B,D) and the styloids lack their connection with the otic capsule (Figs. 4B and 5B,D). The incus and stapes abnormalities would cause abnormalities in hearing.

Dermatocranial alterations These bones contribute to the formation of the ventral surface, lateral wall, and roof of the skull (Couly et al. 1993). Abnormalities in the morphology of the maxillary, palatine, pterygoid, squamosal, and jugal dermatocranial bones alter the temporal wall and the ventral surface of the skull in mutant P0 animals. These abnormal dermatocranial bones are topologically related to the abnormal neuro- 

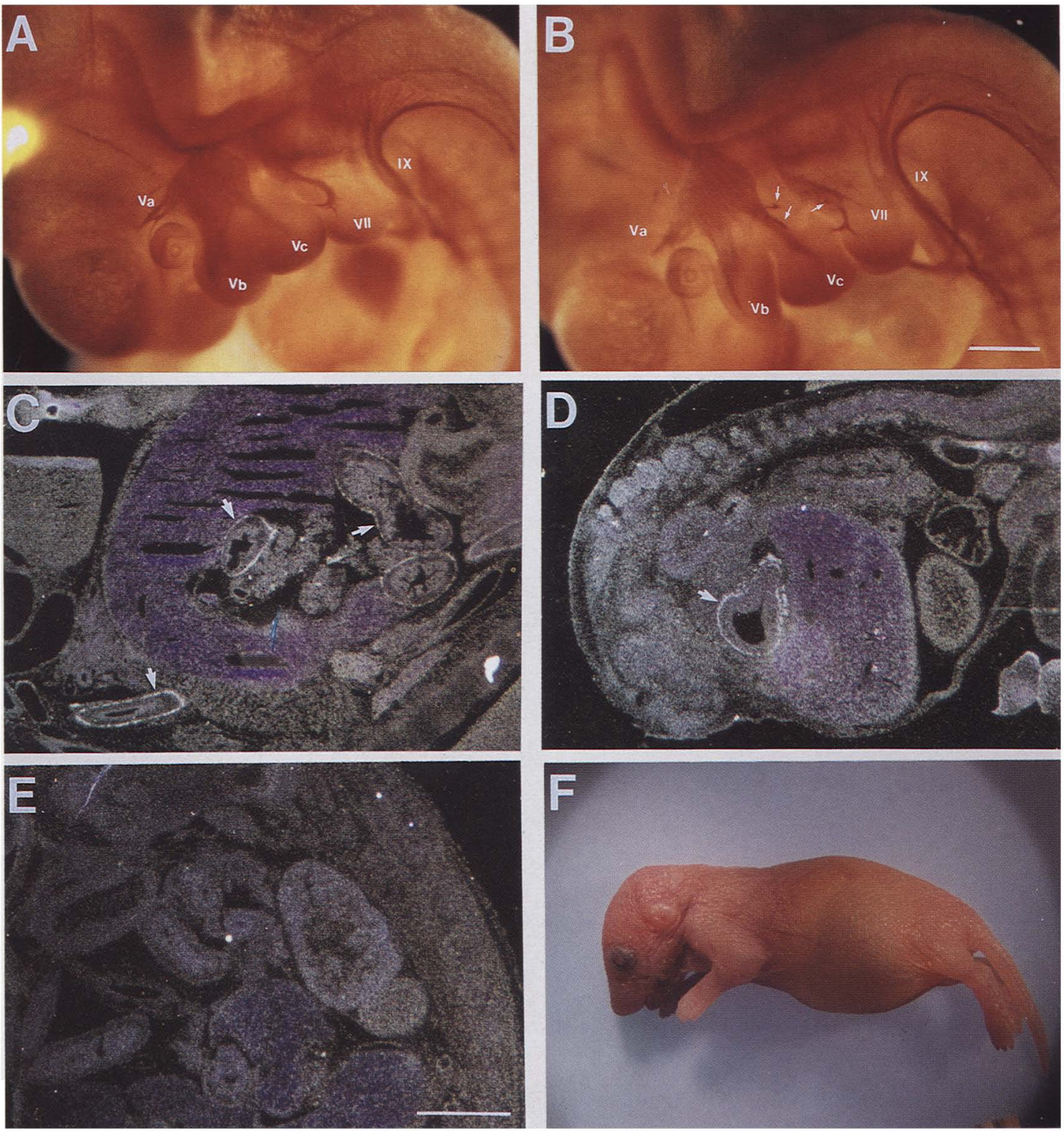

Figure 2. Abnormal phenotypes of neuronal derivatives of the $\mathrm{CNC}$ in $D l x-2$ null mutant animals. $(A, B)$ Abnormal arborization of the mandibular branch of trigeminal nerve in E10.5 mutant embryos. Wild type $(A)$ and homozygous embryos $(B)$ were studied by immunohistochemistry with an anti- $\alpha \mathrm{N}$-catenin antibody. A subpopulation of fibers from the mandibular branch of the trigeminal nerve take an abnormal course (indicated by arrows). Ectopic fiber growth is also seen in the facial (VII) nerve (arrow). Abbreviations: (Va) Ophthalmic branch of trigeminal nerve; $(\mathrm{Vb})$ maxillary branch of trigeminal nerve; (Vc) mandibular branch of trigeminal nerve; (VII) facial nerve; (IX) glossopharyngeal nerve. Bar, $50 \mu \mathrm{m} .(C-E)$ Expression of $D l x-2$ and $D l x-1$ in the enteric neurons of normal and Dlx-2 mutant embryos studied using in situ RNA hybridization. (C) Dlx-1 expression in the enteric neurons of E14.5 wild-type embryos, as indicated by arrows. (D) Dlx-2 expression in the enteric neurons (arrow) of E12.5 wild-type embryos. $(E) D l x-1$ expression is absent in the enteric neurons of a mutant E14.5 embryo, although $D l_{x}-1$ expression in forebrain was not altered in the same embryo (see Fig. 6B). Bar in E, $100 \mu \mathrm{m}$. Efforts to identify abnormalities in the enteric nervous system late in gestation have not uncovered specific defects. For instance, there was normal immunohistochemical staining of the myenteric and Auerbach plexi using anti-nitric oxide synthase (data not shown). (F) Mutant newborn mouse has massive air accumulation in its digestive tract.

cranial and splanchnocranial structures. The roof of the skull appears normal in the mutants.

The zygomatic arch is a characteristic feature of the temporal wall of the mammalian skull. It is formed by an articulation between the squamosal, jugal, and maxillary bones (Fig. 4A,C,E); this structure is altered in the $D l_{X-2}$ mutants. In the mutants, the squamosal and jugal bones are replaced with four bones that we have named bones 1, 2, 3, and 4 (Figs. 4D,F and 5D). These four bones appear at different times during development (bones 1 and 2 on 
Qiu et al.

$\sim$ E15.5 and bones 3 and 4 on $\sim$ E16.5) from independent ossification centers (Fig. 4F; data not shown).

Alterations of three other dermatocranial bones (maxillary, pterygoid, and palatine) transform the morphology of the ventral surface of the skull. In general, the caudal aspects of the palatine bones and the medial parts of the maxillary bones are reduced in size (Fig. $3 F, G$ ). The pterygoids are rostrally displaced, smaller than normal, and contact the BT and Strut (Fig. 3F,G,H). The maxillary, palatine, and pterygoid changes lead to cleft second ary palate in $\sim 80 \%$ of the mutant homozygotes (Fig. $3 \mathrm{~F}, \mathrm{G}, \mathrm{H})$, which predisposes to aspiration of oral contents.
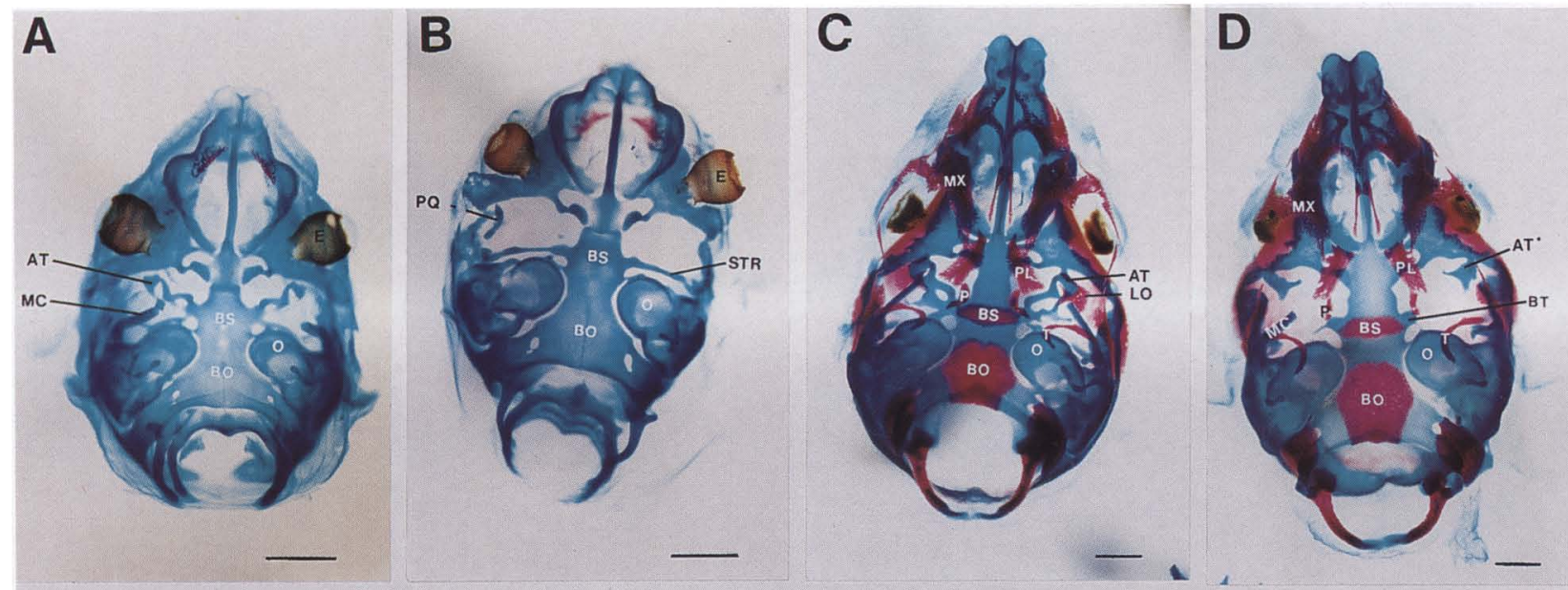
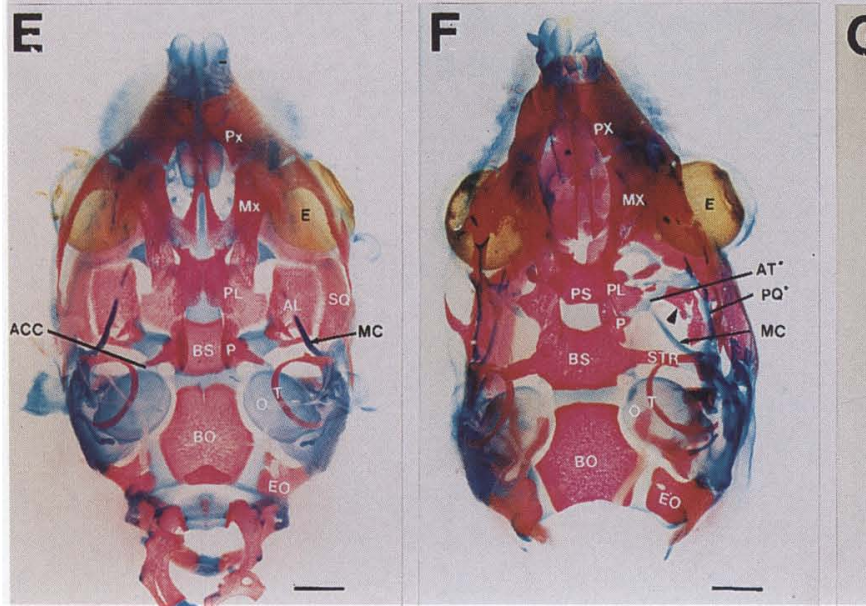

G
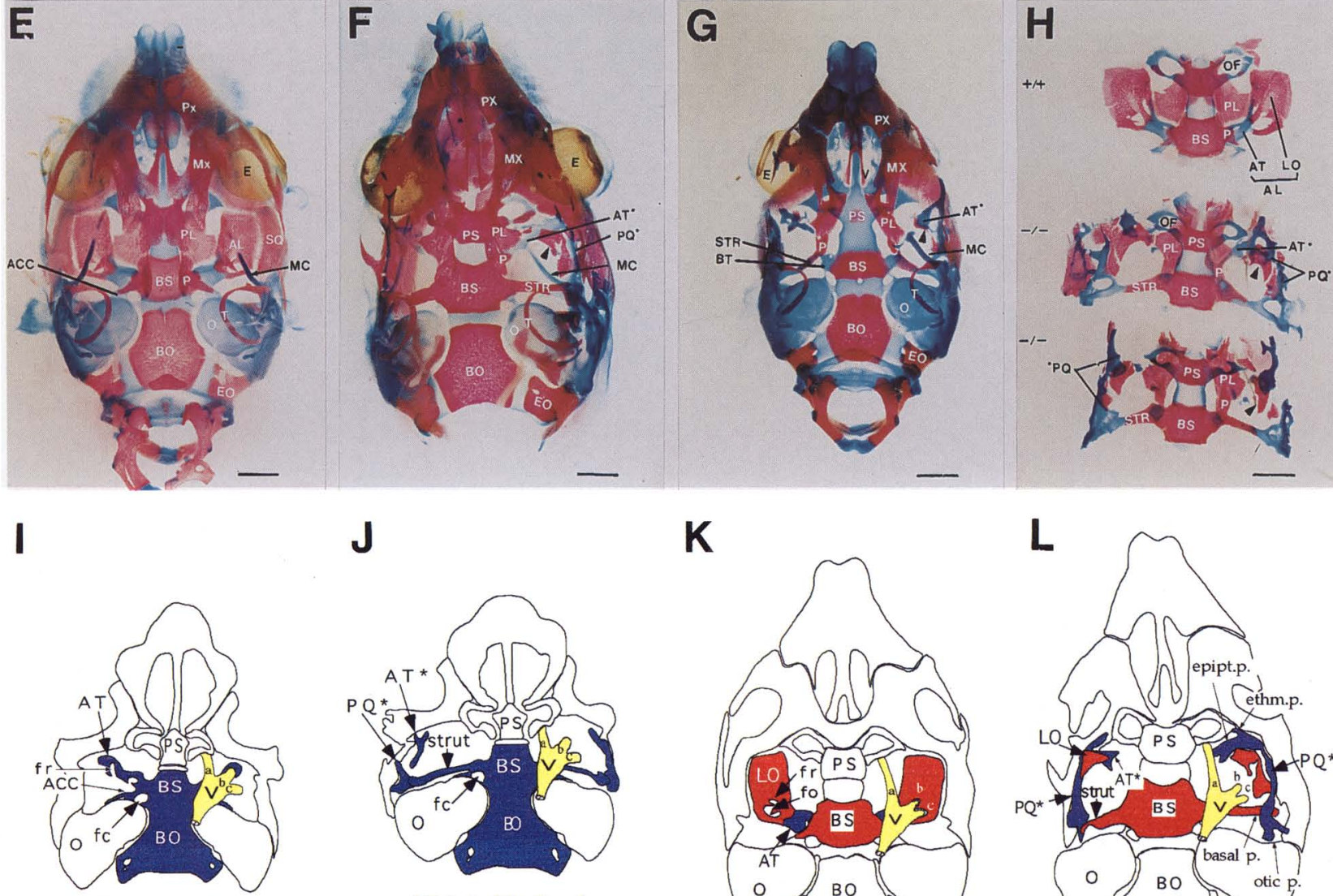

E14.5 WT

\section{J}

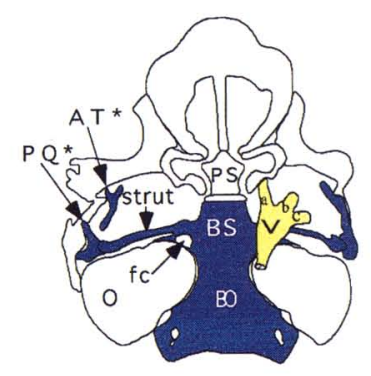

E14.5 Dlx-2 -/-
K

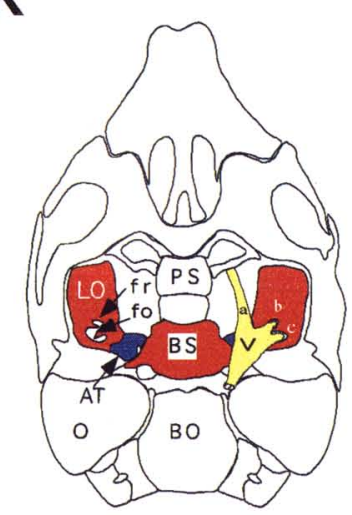

PO WT

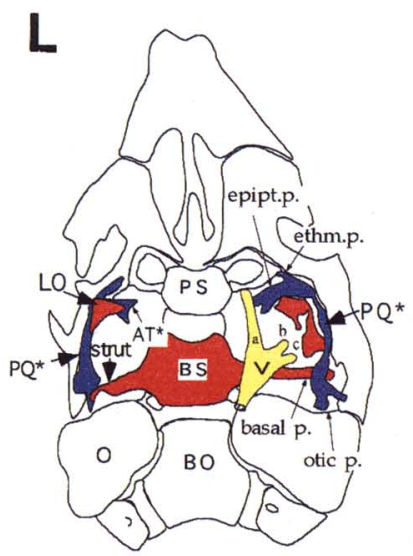

PO Dlx-2 -/-

Figure 3. (See facing page for legend.) 
The Dlx-2 mutants exhibit an abnormal trajectory of the trigeminal nerve

$\mathrm{CNC}$ also participates in the formation of the PNS of the head, including the trigeminal ganglia, the facial ganglia, and the glossopharyngeal ganglia. Dlx-2 is expressed in nests of cells on E9.5, which we have interpreted previously as being in the primordia of the trigeminal and faciacoustical ganglia (Bulfone et al. 1993a). The PNS of E9.5-E11.5 embryos was studied using a monoclonal antibody against $\alpha \mathrm{N}$-catenin, a cadherin-associated molecule preferentially expressed in neurons (Uchida et al. 1994). As shown in Figure 2A, the trigeminal nerve consists of three branches: the ophthalmic, maxillary, and mandibular. Comparison of the Dlx-2-D5/neo homozygotes with their littermates revealed a subtle but consistent change in the arborization pattern only in the mandibular branch. In all of the homozygous mutant mice, as the nerve enters the mandibular arch, some fascicles diverge from the normal pathway and appear to grow toward the lateral surface of the proximal mandibular arch (Fig. 2B). No significant differences have been found in the ophthalmic and maxillary branches of the trigeminal nerve between the normal and homozygous mice. The facial nerve (nerve VII) in the second arch also showed some abnormalities in its branching patterns (Fig. 2B). It is not clear at present whether the abnormal trajectories of the nerves are caused by defective neuronal differentiation or altered enviromental cues.

\begin{abstract}
Dlx-2 loss of function alters differentiation in the olfactory bulb but does not alter regional specification of the forebrain
\end{abstract}

$D l x-2$ is expressed in two spatially restricted domains of the embryonic forebrain beginning at $\sim \mathrm{E} 9.5$ (Bulfone et al. 1993a), suggesting that it could play a role in regional specification, morphogenesis, and differentiation. To evaluate these possibilities, we compared the morphology, histology, and patterns of gene expression in wildtype and Dlx-2-D5/neo homozygous mice at E14.5 and P0. Comparison of cresyl violet-stained tissue sections from these two stages failed to reveal morphological or histological differences.

To determine the fidelity of regional specification in $D l x-2-D 5 /$ neo homozygotes we studied the expression of a number of genes whose expression is restricted to distinct domains. To characterize specification of the domains where $D l_{x}-2$ is expressed we examined the expression of $D l_{x-1}$ and $D l_{x}-5$ (Fig. 6A-D), which are expressed in nearly identical patterns to Dlx-2 (Bulfone et al. 1993b; Simeone et al. 1994). Nkx-2.1 expression was examined because it is coexpressed with $D l x-2$ in the medial ganglionic eminence (MGE) (Fig. 6E,F) (Price et al. 1992). Finally, we examined Emx-1 expression (Fig. $6 \mathrm{G}, \mathrm{H})$ because it is a marker of the dorsal telencephalon (cerebral cortex), a domain that shares a boundary with $D l x-2$ expression in the lateral ganglionic eminence (LGE) (Simeone et al. 1992; Rubenstein and Puelles

Figure 3. Realistic $(A-H)$ and schematic $(I-L)$ ventral view of the wild type $(A, C, E, K, I)$, and $D l x-2$ mutant $(B, D, F, G, J, L)$ newborn skulls at different developmental stages $(A, B, \mathrm{E} 14.5 ; C, D, \mathrm{E} 16.5, E-H, \mathrm{P} 0)$. The dentary, hyoid, and roof bones were removed to enhance the view of the cranial base. $(I-L)$ With particular emphasis on the region containing the trigeminal ganglion (cavum epipterygum). $I$ and $I$ highlight (in blue) some chondrocranial and splanchnocranial components (trigeminal ganglion and nerves are in yellow) of E14.5 embryos. $K$ and $L$ highlight cartilage (blue) and bones (red) derived from chondrocranial and splanchnocranial components of newborns (P0). $I$ and $L$ show loss of the proximal ala temporalis and the appearance of the PQ and strut in the mutant. Details of the chondrocranial alterations: The lateral aspects of the basisphenoid are altered in the mutant mice $(B, D, F, G, H, J, L)$. The overall shape of the basisphenoid is normal, as are its rostral and caudal connections. Laterally the cartilaginous component of the alisphenoid is absent in all of the P0 mutant animals. In addition, an osseous process, which we will term the strut (STR), extends laterocaudally from the basitrabecular process $(\mathrm{BT})(B, F, G, H)$. It connects the basisphenoid with a novel cartilaginous structure (see below). Variations in the STR can be seen, which range from its absence $(D)$ to having a thin connection with the BT $(G)$, although $\sim 80 \%$ of skulls have at least one STR. It is unclear whether the STR is of neurocranial or splanchnocranial origin. Finally, the alicochlear commissure (ACC) is absent in $\sim 50 \%$ of the mutant skulls. In the first arch, only the maxillary derivatives are abnormal in the mutant mice. The ventromedial part of the alisphenoid is absent, and its lateral wing is malformed. This can be seen clearly at E14.5 $(A, B, I, I\rangle$. In the mutants, the alisphenoid $(\mathrm{AL})$ is replaced by a more lateral cartilage $\left(\mathrm{AT}^{\star}\right)$, and an associated membrane bone (arrowheads in $\left.F, G, H\right)$. In addition the incus is misshapen in all of the mutant animals (missing its short process) (Fig. 4G,H), and it never articulates with the stapes. In about half the cases, the incus is fused at the position of its short process to a new elongated cartilage (Figs. 4H and 5D), that is lateral to the basisphenoid $(F, G, H$; also Fig. $5 \mathrm{~B}, \mathrm{E})$. The shape of this new cartilage is somewhat variable, but its location and relationship with other bones are constant. In some cases, it is a continuous cartilage $(F, G, H$; and Fig. $4 \mathrm{~B})$, whereas in the other cases it is discontinuous $(H$; and Fig. 4D). The new cartilage also articulates with several other structures. Its rostral process contacts the maxillary bone $(F, G$; and Fig. $4 \mathrm{~B})$; its ventromedial process extends towards the palatine bone $(F, H)$. The new cartilage also has a caudal ventromedial process that is continuous with the (STR) $(F, G, H, L$; and Fig. 5B). Finally, its dorsal surface contacts the dermal bones in the temporal wall $(D, F, G$; and Figs. $4 \mathrm{D}$ and $5 \mathrm{D})$. The shape, position, and articulations of the new cartilage lead us to hypothesize that it is homologous to the pterygoquadrate, the splanchnocranial element of the maxillary arch of nonmammalian vertebrates. Details of dermatocranial alterations: In general, the caudal aspects of the palatine bones and the medial parts of the maxillary bones are reduced in size $(F, G)$. The pterygoids are rostrally displaced, smaller than normal, and contact the BT and STR $(F, G, H)$. Abbreviations: (AL) Alisphenoid; (AT) ala temporalis; (basal p.) basal process; (BO) basisoccipital; (BS) basisphenoid; (BT) basitrabecular process; (E) eyeball; (EO) exo-occipital; $\left(\mathrm{AT}^{*}\right)$ epipterygoid process; (ethm. p.) ethmoid process; (fc) carotid foramen; (fo) foramen ovale; (fr) foramen rotundum $_{\text {; }}$ ) incus; (J) jugal; (lo) lamina obturans; (M) malleus; (Mc) Meckel's cartilage; $(\mathrm{Mx})$ maxilla; $(\mathrm{O})$ otic capsule; (OC) occipital; (OF) optic foramen; (otic p.) otic process; (PL) palatine; (PO) postorbital; (PQ) pterygoquadrate; (PS) presphenoid; (P) pterygoid; (Px) premaxillary; (QJ) quadratojugal; (S) stapes; (SQ) squamosal; (Sty) styloid; (T) tympanic; (V) trigeminal ganglia (a, opthalmic; b, maxillary; c, mandibular branches). Bar, $1 \mathrm{~mm}$. 


\section{Qiu et al.}

1994). These studies, together with the whole-mount in situ RNA hybridization with Dlx-1 and Dlx-5 in E10.5 embryos (I.G. Ghattas and J.L.R. Rubenstein, unpubl.), did not reveal abnormalities in the expression of these molecular markers and suggest that regional specification within the forebrain is not significantly altered.
To study cellular differentiation in the Dlx-2 expressing structures, we examined the expression of several proteins that are found in specific types of neurons. These include nitric oxide synthase, tyrosine hydroxylase, parvalbumin, calbindin, calretinin, substance $P$, vasointestinal peptide, neuropeptide Y, L-enkephalin, and

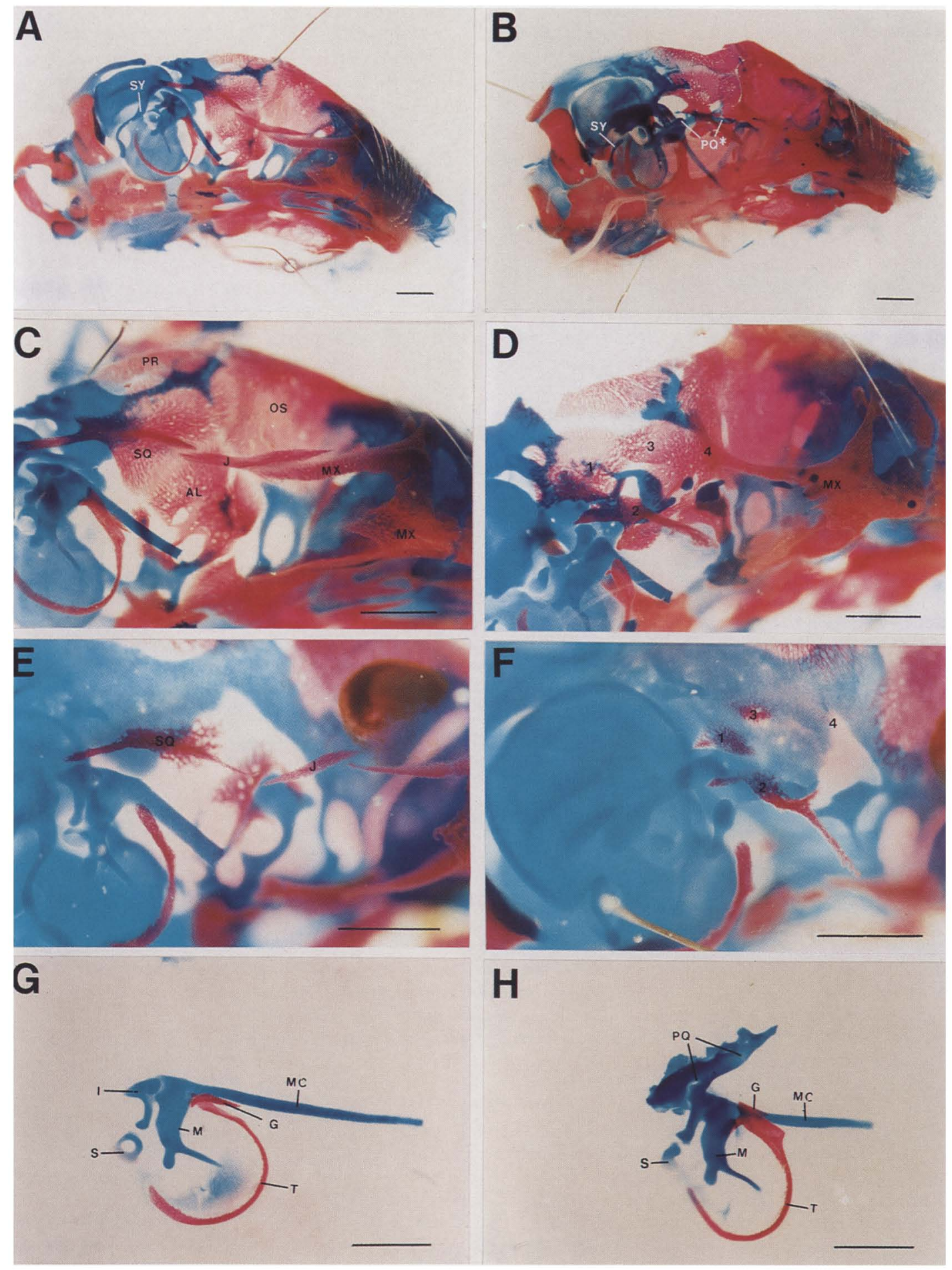

Figure 4. (See facing page for legend.) 
choline acetyltransferase. Immunohistochemical analysis of tyrosine hydroxylase (TH) expression is clearly abnormal in the olfactory bulb of Dlx-2-D5/neo homozygotes at P0 (Fig. 7). Wild-type and heterozygote animals express $\mathrm{TH}$ in their periglomerular neurons, whereas $\mathrm{TH}$ expression was lost in eight independent $D / x-2-D 5 /$ neo homozygotes. $D 1 x-1$ is also expressed in the periglomerular cells (Salinas and Nusse 1992). In situ RNA hybridization shows that $D l_{X}-1$ continues to be expressed in the region of the periglomerular cells in $D l x-2-D 5 /$ neo homozygotes (data not shown). This suggests that the periglomerular cells are present but that either their state of differentiation or identity has been altered.

\section{Discussion}

Dlx-2 function is required in a subset of the tissues where it is expressed

We show that loss of $D l_{x}-2$ function affects a subset of the tissues where it is expressed. For instance, whereas Dlx-2 mutants have profound craniofacial abnormalities, limb development is normal (Fig. 2F), despite its expression in the ventral ectoderm of the limb bud (Bulfone et al. 1993a) and the important role of DIl in development of the fly limb (Cohen et al. 1989).

The fact that many $D l x$-2-expressing tissues are unaffected in $D l x-2-D 5 /$ neo homozygotes implies a genetic redundancy that may involve the other Dlx genes. The homeo domain sequences of the five known murine DLX proteins are nearly identical (Porteus et al. 1991; Price et al. 1991; Robinson et al. 1991; Simeone et al. 1994), suggesting that each of them is capable of binding to similar target nucleotide sequences. In addition, $D l_{x}-1, D l_{x}-2$, $D l x-5$, and $D l_{X}-6$ have similar patterns of expression (Price et al. 1991; Robinson et al. 1991; Bulfone et al. 1993b; Simeone et al. 1994), which further implies that loss of function of one DlX gene can be at least compensated partially for by the presence of the other Dlx homologs. However, because loss of $D 1 x-2$ function leads to severe abnormalites, we hypothesize that each of these genes has a unique function in a subset of the tissues where it is expressed. The unique and redundant functions of the Dlx-1 and Dlx-2 genes are clearly demon- strated by comparing the phenotypes of $D l x-1$ mutant, DlX-2 mutant, and $D l_{X}-1$ and $D l_{X}-2$ double mutant animals (M. Qiu, A. Bulfone, and J.L.R. Rubenstein, unpubl.).

\section{Loss of Dlx-2 expression results in abnormal development of a specific forebrain cell type}

$D l_{x}-2$ expression in the embryonic forebrain is temporally and spatially regulated (Bulfone et al. 1993b; Puelles and Rubenstein 1993; Rubenstein et al. 1994). However, we have not found any evidence for the role of $D / x-2$ in regional specification and morphogenesis. On the contrary, we have demonstrated that in most $D 1 x$-2D5/neo homozygotes, expression of $\mathrm{TH}$ in the P0 olfactory bulb is not detectable (Fig. 7). In the olfactory bulb this enzyme is predominantly expressed in the periglomerular cells (Farbman 1991). The absence of TH expression could be caused by several mechanisms. These include absence of all or a subset of periglomerular cells or abnormal expression of $\mathrm{TH}$ in these cells. The absence of periglomerular cells could be caused by cell death or by failure to migrate into the olfactory bulb from the ventricular zone of the anterior lateral ventricle (Luskin 1993). Abnormal expression of TH could be attributable to an immature phenotype or to an alternate cell fate, or to dependence of $\mathrm{TH}$ expression on the DLX-2 protein. Alternatively, there is evidence that TH expression depends on normal innervation of the periglomerular cells by the olfactory afferents (Farbman 1991). Thus, Dlx-2 could alter the ability of the periglomerular cells to form functional synapses with the olfactory afferents. We observe $D / x-1$ expression in the region of the periglomerular cells in the $D l x-2-D 5 /$ neo homozygotes suggesting that the precursors for these cells have migrated into the correct position. We are presently performing experiments designed to study the differentiation and innervation of the periglomerular cells.

\section{Defects in the skull, trigeminal ganglion, and enteric nervous system show that $\mathrm{Dlx}-2$ has an essential role in the differentiation of the CNC}

Dlx-2 is expressed in the CNC from the rhombencephalon beginning $\sim$ E8.5 (Bulfone et al. 1993b; K. Shimam-

Figure 4. Lateral views of the skull and middle ear bones. (Left) Wild-type $(A, C, E, G) ;($ right $)$ homozygous mutant $(B, D, F, H)$. In the mutant $(B)$, the elongated cartilage ( $\left.\mathrm{PQ}^{*}\right)$, extends from incus to the maxillary region. The styloid cartilage (SY) is normally connected to otic capsule $(A)$ but is separated from the otic capsule in the mutants $(B) .(C, D)$ The temporal region in greater detail. $(C)$ is a higher magnification of $A$, whereas $D$ shows the temporal wall in a mutant different than in $B$. In the $D l_{X}-2$ mutants, the squamosal (SQ) and jugal ( $\mathrm{J}$ ) are replaced with four new bones, 1, 2, 3, and 4 . In the region of the squamosal are two bones (1 and 2). Just rostral to bones 1 and 2 are bones 3 and 4 , whose shapes resemble bones 1 and 2 . Also note that the ventromedial part of the alisphenoid (AL) is missing in $D .(E, F)$ The temporal walls of the wild-type and mutant El6.5 embryos. Four independent ossification centers $(1,2,3,4)$ can be seen in the mutant, whereas only two can be seen in the wild type $(\mathrm{SQ}, \mathrm{J}) .(G, H)$ The middle ear bones dissected from normal $(G)$ and homozygous mutant $(H)$ samples. The stapes $(\mathrm{S})$ is misshapen and has lost its central hole in the mutants. Also, the incus is fused with the pterygoquadrate (PQ). The malleus (M), tympanic (T), and gonial $(G)$ bones appear to be normal in the mutants. The different shapes of the gonial bones are attributable to different photographic angles. Additional abbreviations: (Mx) maxillary; (OS) orbitosphenoid; (PR) parietal. Bar, $1 \mathrm{~mm}$. 
Qiu et al.

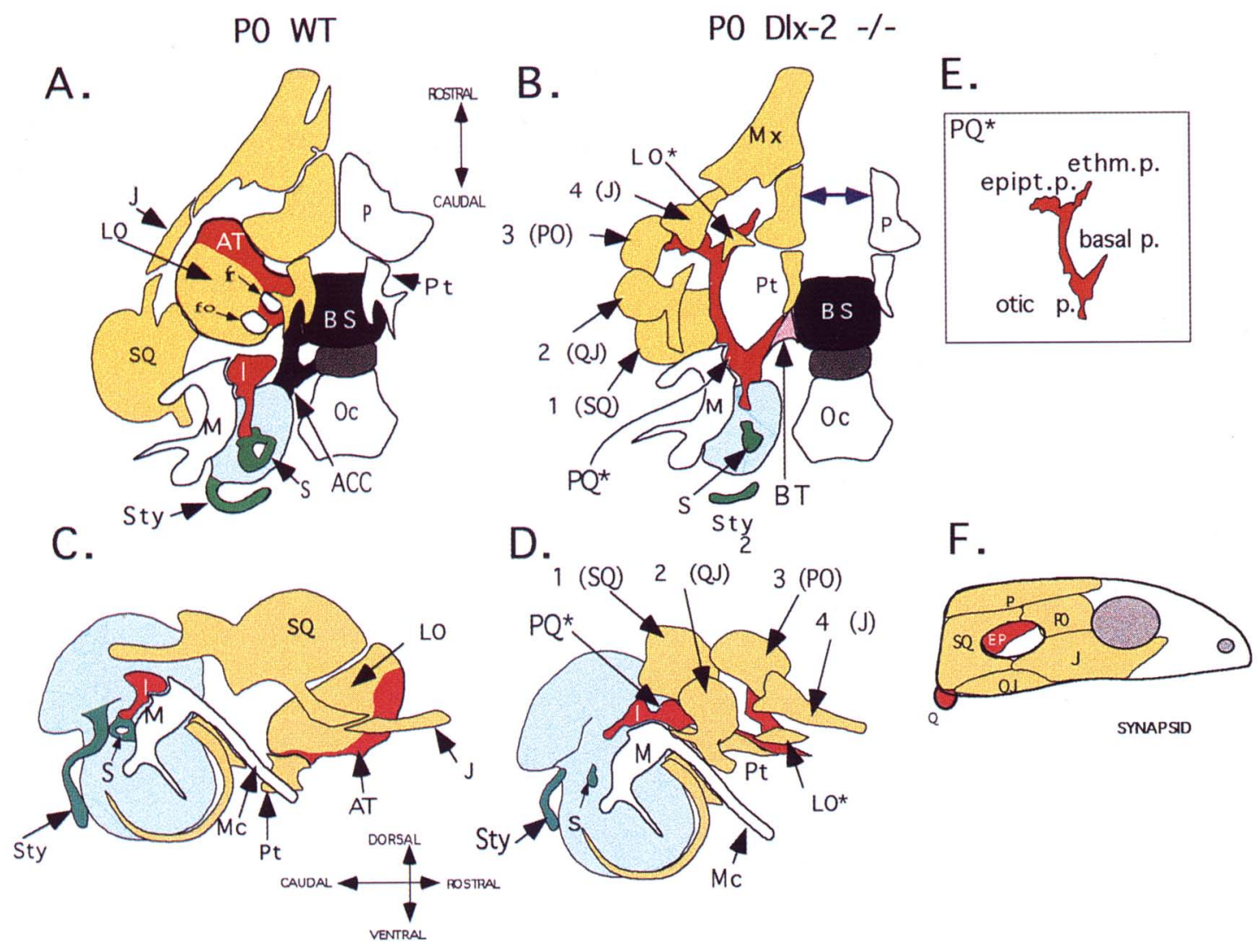

Figure 5. Comparison of the alterations in $D I X-2$ mutant skulls to wild-type mouse and synapsid skulls. $(A, B)$ ventral view of base of skull of wild-type and mutant PO skulls; $(C, D)$ lateral view. (Yellow) dermatocranium; (red) maxillary splanchnocranium; (green) second arch splanchnocranium; the blue arrow shows the cleft of palatine bones in the mutants. $(E)$ The four processes of the pterygoquadrate in the mutant mice. $|F|$ The temporal wall of synapsids, the reptilians ancestors of mammals; cf. the arrangement of the dermatocranial bones in the mutant $(D)$. Development, evolution, and alteration of the alisphenoid. The alisphenoid has two components: splanchnocranial and membranous. During its development, the splanchnocranial part is known as the ala temporalis (AT) (Fig. 3A,C). This cartilage may correspond to the epipterygoid component of the pterygoquadrate found in mammal-like reptiles (Presley et al. 1976; Presley 1981; Novacek 1993). The membrane bone component of the alisphenoid may be equivalent to the lamina obturans (LO) found in monotreme mammals (Fig. 3C, H,L). At present, it is uncertain whether this membrane bone is novel to mammals or whether it is related to a bone found in the reptile group (cynodonts) from which mammals are derived (Presley and Steel 1976; Presley 1981; Novacek 1993). In the mutants, the medial part of AT (splanchnocranial precursor of the alisphenoid) is missing, but a lateral cartilaginous fragment remains $\left(\mathrm{AT}^{*}\right.$, Fig. 3D,F,G,H). We suggest that this fragment is a remnant of the AT, as supported by its location and constant association with a dermal bone in the position of lamina obturans (see arrowhead in Fig. 3F, G, H). Abbreviations: (ACC) alicochlear commissure; (AL) alisphenoid; (BO) basisoccipital; (BS) basisphenoid; (BT) basitrabecular process; (EO) exo-occipital; (EP) epipterygoid; (epipt. p.) epipterygoid process $\left(\mathrm{AT}^{\star}\right)_{\text {; }}$ (ethm. p.) ethmoid process; (fo) foramen ovale; (fr) foramen

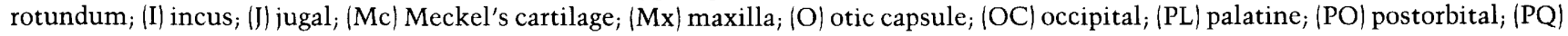
pterygoquadrate; (P) pterygoid; (Q) quadrate; (QI) quadratojugal; (S) stapes; (SQ) squamosal; (Sty) styloid; (T) tympanic.

ura and J.L.R. Rubenstein, unpubl.). This is consistent with alterations in the morphology of first and second branchial arch-derived structures in the $D l_{X}-2$ mutants. CNC contributes to several tissues, including bone, cartilage, cranial ganglia, enteric neurons, meninges, and muscle in the arches (Noden 1988; Langille et al. 1993; LeDouarin et al. 1993). Loss of Dlx-2 function results in defects in many of these derivatives, including specific bones and cartilages, trigeminal axons, and enteric neurons. The largest abnormalities lie in the skull whose defects we discuss separately.

Although mutation of $D / x-2$ causes severe defects in the CNC-derived tissues, the brain and other Dlx-2-positive tissues have more subtle or no abnormalities. Similar findings are found for mutations of other homeo box genes such as Hox-a2, Hox-a3, and Msx-1/Chisaka and
Capecchi 1991; Gendron-Maguire et al. 1993; Rijii et al. 1993; Satokata et al. 1994). It appears as though the CNC is particularly sensitive to mutations in homeo box genes, whereas redundancy may protect the CNS from major phenotypic alterations attributable to mutations in a single homeo box gene. This implies that the derivatives of the CNC are capable of evolving more rapidly than the CNS, which is consistent with the idea that there may be a selective advantage to being able to modify the fate of the CNC while only slightly altering the fate of the CNS.

Dlx-2 is part of the homeo box gene code for branchial arch morphogenesis: role in proximodistal patterning

The role of homeo box genes in craniofacial development 
Table 1. A summary of abnormalities of craniofacial bones in the Dlx-2 mutants

\begin{tabular}{|c|c|c|c|c|}
\hline & \multicolumn{2}{|c|}{ First $\operatorname{arch}^{a}$} & \multicolumn{2}{|r|}{ Second $\operatorname{arch}^{a}$} \\
\hline & proximal & distal & proximal & distal \\
\hline Splanchnocranium & $\begin{array}{l}\text { incus (quadrate) }(-) \\
\text { alisphenoid }\left(\mathrm{AT}^{*}\right)^{\mathrm{b}}(-)\end{array}$ & $\begin{array}{l}\text { Meckel's cartilage } \\
\text { malleus }\end{array}$ & $\begin{array}{l}\text { stapes }(-) \\
\text { styloid }(-)\end{array}$ & $\begin{array}{l}\text { hyoid (upper body and lesser } \\
\text { horns) }\end{array}$ \\
\hline Dermatocranium & $\begin{array}{l}\text { maxillary }(-) \\
\text { jugal }(-) \\
\text { squamosal }(-) \\
\text { palatine }(-) \\
\text { pterygoid }(-)\end{array}$ & $\begin{array}{l}\text { mandible } \\
\text { tympanic } \\
\text { gonial }\end{array}$ & & $\begin{array}{l}\text { no dermal bones are related } \\
\text { to the second arch }\end{array}$ \\
\hline
\end{tabular}

a - ) Bones affected by the Dlx-2 mutation.

$\mathrm{b}\left(\mathrm{AT}^{\star}\right)$ Ala temporalis component of the alisphenoid.

is suggested by their temporally and spatially restricted patterns of expression. Mutations in three Hox genes (Hoxa-1, Hoxa-2, and Hoxa-3) each cause distinct sets of craniofacial abnormalities. A combinatorial Hox code has been suggested for the control of the regional patterning of branchial arches (Krumlauf 1993), and the involvement of Hox genes in the specification of rostrocaudal identities of the branchial arches is supported by the loss of function of Hoxa-2, which causes a homeotic transformation of the second arch into first-arch structures (Gendron-Maguire et al. 1993; Rijii et al. 1993).
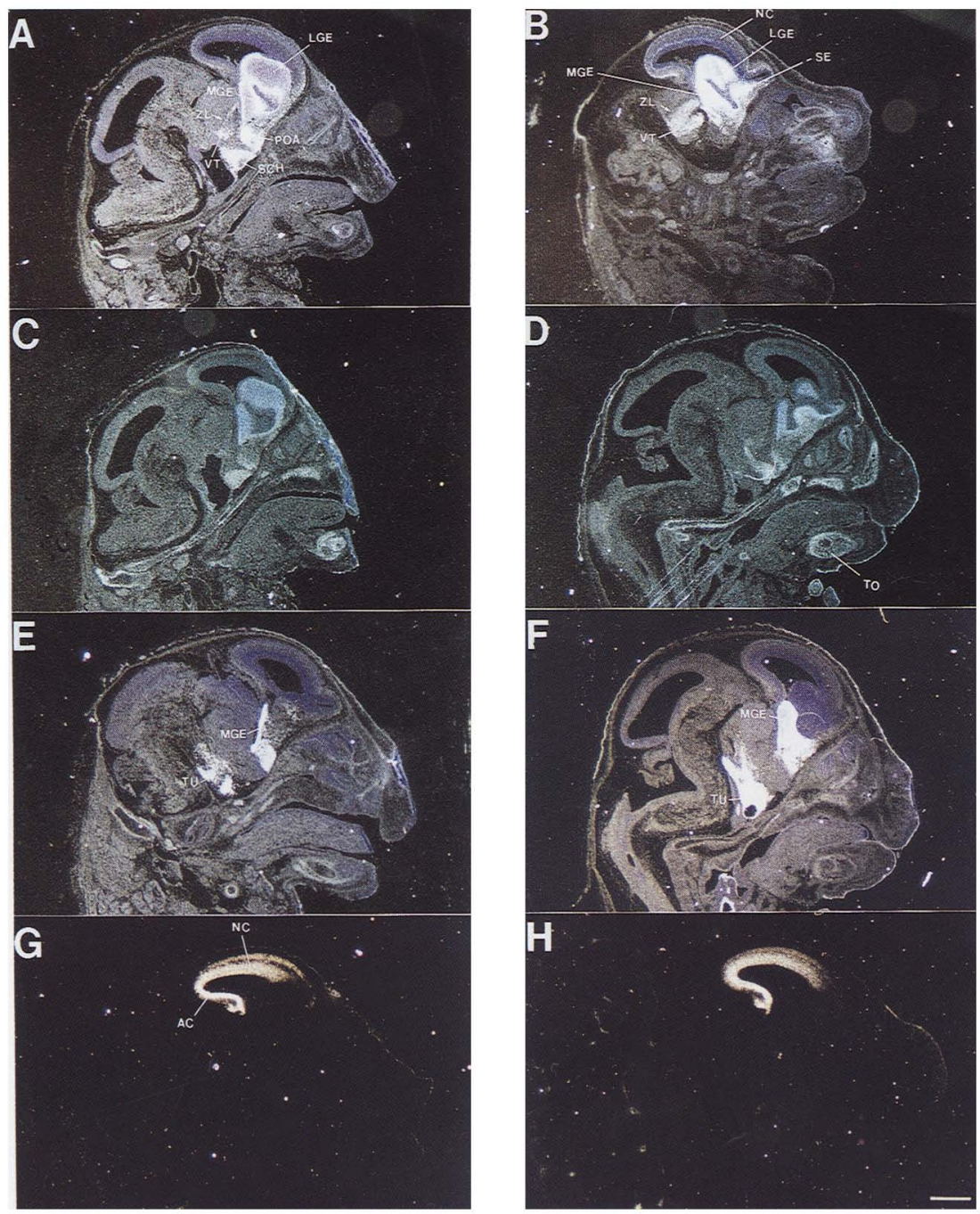

Figure 6. Expression of homeo box genes in the head of wild-type $(A, C, E, G)$ and $D l x-2$ mutant $(B, D, F, H)$ E14.5 embryos, studied by in situ RNA hybridization. No significant differences in the expression of these genes have been detected between wild-type and $D I x-2$ mutant animals. Parasagittal sections were hybridized with $D l x-1(A, B), D l x-5(C, D), N k x-2.1(E, F)$, and Emx-1 $(G, H)$ cRNA probes. Bar, in $H, 50$ $\mu \mathrm{m}$. Abbreviations: $(\mathrm{AC})$ archicortical primordium; (LGE) lateral ganglionic eminence; (MGE) medial ganglionic eminence; (NC) neocortical primordium; (POA) preoptic area; $(\mathrm{SCH})$ suprachiasmatic area; $(\mathrm{SE})$ septum; (TO) tooth primordium; (TU) tuberal hypothalamus; (VT) ventral thalamus; (ZL) zona limitans. 
Figure 7. Lack of $\mathrm{TH}$ expression in the periglomerular neurons in the olfactory bulb of the DIx-2 mutants. Frontal sections of the wild-type and mutant newborn pups (P0) were used for immunohistochemistry with an anti- $\mathrm{TH}$ antibody. $\mathrm{TH}$ expression is detected in the periglomerular neurons of the wild-type pups $(A, C)$, but not in those of mutants $(B, D)$. $C$ and $D$ show the basal regions of $A$ and $B$, respectively, at higher magnification (2.5-fold).
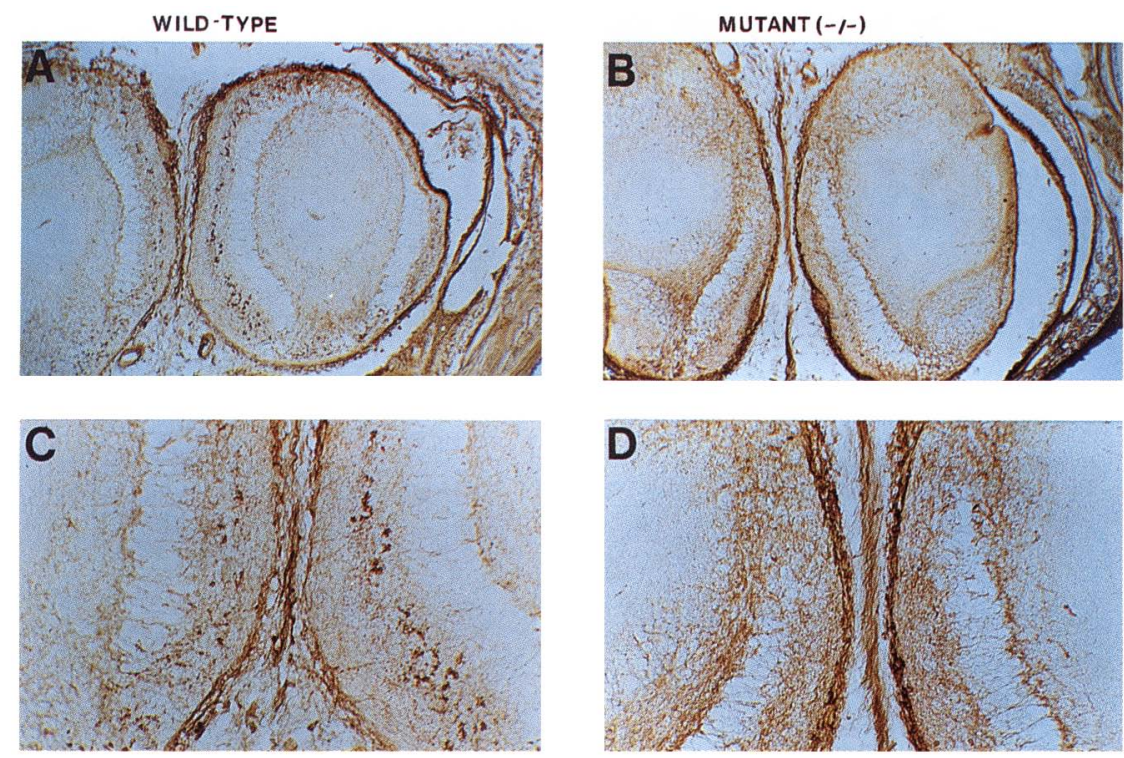

Non-Hox homeo box genes may be involved in other processes of regional patterning, such as proximal-distal and medial-lateral patterning. In addition, the Hox genes are not expressed in the first arch, where $D l x-2$ and other genes are candidate regulators. These genes include the entire Dlx family (Porteus et al. 1991; Price et al. 1991; Robinson et al. 1991; Beauchemin and Savard 1992; Dirkson et al. 1993; Papalopulu and Kintner 1993; Akimenko et al. 1994; Simeone et al. 1994; Zhao et al. 1994), Msx-1 and Msx-2 (MacKenzie et al. 1991), MHox (Cserjesi et al. 1992), and Gsc (Gaunt et al. 1993). These homeo box genes have distinct and overlapping expression patterns in the branchial arches. For instance, $M s X-1$ and $M s x-2$ are expressed in the mesenchyme of the medial part of the arches (MacKenzie et al. 1991; Mina et al. 1995|, whereas expression of the Dlx genes is localized more laterally (Bulfone et al. 1993a; Robinson and Mahon 1994; I.G. Ghattas and J.L.R. Rubenstein, unpubl.). Their complementary expression patterns could explain why the Msx-1 and Dlx-2 mutations affect different craniofacial tissues (Satokata and R. Maas 1994; this paper). Furthermore, each Dlx gene has a unique expression pattern in the first two arches of the mouse and zebrafish (Bulfone et al. 1993; Akimenko et al. 1994; Robinson and Mahon 1994; I.G. Ghattas and J.L.R. Rubenstein, unpubl.). Although all of the Dlx genes are expressed in the mandibular component (distal) of the first arch and the distal second arch, only $D l_{x}-2$ and $D l_{x}-1$ have expression in the mesenchyme of the maxillary component (proximal) of the first arch and proximal second arch (I.G. Ghattas and J.L.R. Rubenstein, unpubl.|. As described in this report, only the proximal structures of the first and second arches are affected in the Dlx-2 mutants. The lack of alterations in the distal part of the first and second arches may be because Dlx genes, such as Dlx-3, $D l x-5$, and $D l x-6$ can compensate for the loss of Dlx-2 in these regions.
Splanchnocranial and dermatocranial malformations in Dlx-2-D5/neo homozygotes are consistent with a transformation toward a reptilian-like morphology

Dlx-2-D5/neo homozygotes have distinct splanchnocranial and dermatocranial abnormalities (see Table 1). The splanchnocranium and dermatocranium of the proximal first and second branchial arches is either deleted or misshapen. In this section, we interpret these alterations in the context of evolution of the skull. In this regard, mutations of Hoxa-2 and MHox also lead to skull alterations that have been interpreted to cause evolutionarily related skeletal transformations (Gendron-Maguire et al. 1993; Rijii et al. 1993; Martin et al. 1995).

The splanchnocranial bones and cartilages of the mouse are related to a cartilage that is present in each branchial arch in primitive vertebrates (Barghusen et al. 1979). The second arch (hyoid arch) contains Reichardt's cartilage, which differentiates distally into the lesser hyoid horns and the styloid ligaments and proximally into the stapes and styloid. The first arch cartilage is subdivided into distal and proximal parts. In mammals the distal part forms Meckel's cartilage and the malleus; the proximal part forms the incus and the alisphenoid, which are hypothesized to have evolved from the pterygoquadrate cartilage of lower vertebrates (Presley and Steel 1976; de Beer 1985; Feduccio and McCrady 1991; Novacek 1993).

Dlx-2-D5/neo homozygotes display alterations in the proximal derivatives of the splanchnocranium from arches 1 and 2 (Table 1). Thus, from the first arch the alisphenoid and incus are abnormal and from the second arch the stapes and styloid are abnormal. Distal arch 1 (Meckel's cartilage and the malleus) and arch 2 (lesser hyoid horns) structures are normal.

Most of the alisphenoid is missing in this mutant 
(Figs. 3F-H and 4D). The alisphenoid is unique to mammals; its origin is of considerable interest, as variations in its form characterize phylogenetic relationships in the evolution of mammals (Presley 1981). Furthermore, it is generally held that the alisphenoid is composed of two components: its ventrolateral part from the pterygoquadrate cartilage (splanchnocranium) and its dorsolateral blade from a membrane bone (Presley and Steel 1976; Novacek 1993). Our data of wild-type mouse development support this idea (see legend to Fig. 5 for details).

Another major change in the splanchnocranium of the mutants is the presence of a lateral cartilaginous bar. On the basis of its shape and relationships with other skeletal elements (see Results), we hypothesize that this cartilage is the homolog of the pterygoquadrate cartilage of lower vertebrates. The pterygoquadrate has four characteristic processes (otic, basal, epipterygoid, and ethmoid) (Barghusen and Hopson 1979); each is present in this new cartilage (Fig. 5E). The new cartilage is fused with the otic capsules (otic process). The connection of the new cartilage with the basisphenoid (the strut) could be homologous to the reptilian basal process. Another process extends medially to contact the palatine and pterygoid bones (epipterygoid process, which we have labeled as $\mathrm{AT}^{\star}$ because of the similarity in its position to part of the AT in the wild-type animals). Finally, its rostral pole enters the ethmoidal region, similar to ethmoid process of primitive vertebrates.

In at least half of the cases, the pterygoquadrate cartilage is continuous with the incus, the mammalian homolog of the quadrate, which is an element of the pterygoquadrate cartilage of primitive vertebrates (Fig. 4H). In mammal-like reptiles (cynodonts), the structures that are believed to be derived from the pterygoquadrate (epipterygoid and quadrate) are separate elements (Fourie 1974).

The dermatocranium is also abnormal in all of the $D l x-2$ mutants. The jugal and squamosal bones, which normally constitute the temporal wall in the wild-type mice, are replaced by four bones in the mutants (Figs. 4 and 5A-D). The shapes and positions of the new bones can be conceived as being related to the four dermal bones (squamosal, quadratojugal, postorbital, and jugal) in the temporal wall of reptiles and mammal-like reptiles (Figs. 4 and 5D,F) (Barghusen et al. 1979; Rieppel 1993).

Most of the proximal first-arch skeletal abnormalities found in the $D l_{X}-2$ mutants can be conceived as a transformation of this region of the skull toward a reptilian form. If this hypothesis is correct, it predicts that $D 1 x-2$ has an important role in the evolution of the proximal first arch. However, given that orthologs of $D l x-2$ appear to be present in fish (Akimenko et al. 1994), frogs (Papalopulu et al. 1993), and chickens (G.P. Keleher and J.L.R. Rubenstein, unpubl.), it is likely that the mammalian $D l x-2$ is not a novel gene. Thus, it is more probable that during vertebrate evolution, either the regulation of $D l x-2$ expression and/or the response or activity of its target genes has been modified to yield the skull structures that are distinctive to each vertebrate class.

\section{Materials and methods}

Construction of the Dlx-2 targeting construct

Genomic DNA encoding the $D l x-2$ gene was isolated by screening a genomic library (from Anton Berns, Amsterdam, The Netherlands) made from the liver of strain 129 mice using a Dlx-2 cDNA (Porteus et al. 1991) as a probe. The targeting construct was made using pBS $\mathrm{KS}-$ as the cloning vector. The organization of the targeting vector is shown in Figure 1A. Briefly, a $4.5-\mathrm{kb}$ Dlx-2 fragment (upstream of the HincII site in the first exon of $\left.D l_{x}-2\right)$ was ligated $5^{\prime}$ to the positive selection gene cassette (PGKneo) (Tybulewicz et al. 1991). An 8-kb XbaI genomic fragment was subcloned $3^{\prime}$ of the PGKneo cassette. The Dlx-2 replacement vector contains a $\sim 5$-kb deletion that includes the homeo box and 3 ' coding sequences. Finally, a negative selection gene cassette [PGK-thymidine kinase (PGKtk); Johnson et al. (1989)] was inserted $5^{\prime}$ to the $4.5-\mathrm{kb}$ Dlx-2 fragment.

\section{Generating recombinant ES clones}

The targeting vector $(20 \mu \mathrm{g})$ was linearized and introduced into the ES cells by electroporation $(500 \mu \mathrm{F}, 240 \mathrm{~V})$; the cells were cultured on UV-irradiated neo-resistant STO cells. A new line of ES cells (JM-1), generated from 129/SvJ mice (J.J. Meneses and R.A. Pedersen, unpubl.) was used in these experiments. Two days following electroporation, the ES cells were grown in 300 $\mu \mathrm{g} / \mathrm{ml}$ of G418 (GIBCO) and $0.2 \mu \mathrm{M}$ FIAU (Bristol Meyers) on STO cells for 1 week. The G418 and FIAU double-resistant clones were then picked, trypsinized, and divided into two plates for further culture; one plate was used for genomic DNA extraction and the cells in the replica plate were frozen. Genotyping of the clones was performed using Southern analysis. For this purpose, DNA was isolated from individual clones using a Biotecx kit, digested with EcoRI and SalI, separated on a $0.8 \%$ agarose gel, transferred to Duralon UV membrane (Stratagene), and hybridized with probe $\mathrm{A}$ or B (Fig. 1A) under high stringency conditions (Sambrook et al. 1989).

\section{Generation and genotyping of the Dlx-2 mutant mice}

The ES cell lines containing mutations in one of the Dlx-2 alleles were karyotyped and then injected into blastocysts isolated from $\mathrm{C} 57 \mathrm{BL} / 6 \mathrm{~J}$ mice, which were reimplanted into the uteri of pseudopregnant CD-1 mice (Joyner 1994). Male chimeras were mated with C57BL6 females; germ-line transmission was assessed by scoring the $F_{1}$ offspring for the agouti phenotype and was verified by Southern analysis (see below). Dlx-2$D 5 /$ neo homozygotes from four independent cell lines 139,73 , 285 , and 301) had indistinguishable phenotypes in both hybrid $(129 \times \mathrm{CD} 1)$ and inbred (129) genetic backgrounds. We performed a detailed phenotypic characterization on the progeny of two founder ES cell lines (39 and 73).

$F_{1}$ mice heterozygous for the Dlx-2 mutant allele were intercrossed to produce $F_{2}$ progeny. Southern analysis and/or PCR was used to genotype these offspring. For Southern analysis, the genomic DNA was digested with $\mathrm{BamH1}$ and hybridized with probe $\mathrm{B}$ (Fig. 1A). For genotyping by PCR, two sets of PCR primers were used. The primers for the wild-type allele amplify a fragment located in the $3^{\prime}$-coding region that is deleted in the mutant animals; their sequences are $5^{\prime}$-TCCGAATAGTGAACGGGAAGCCAAAG-3' and 5'-CAGGGTGCTGCTCGGTGGGTATCTC- $3^{\prime}$. The PCR conditions for these primers are $94^{\circ} \mathrm{C}$ for $2 \mathrm{~min} ; 35$ cycles of $94^{\circ} \mathrm{C}$ for $1 \mathrm{~min} ; 58^{\circ} \mathrm{C}$ for $1 \mathrm{~min}$; and $72^{\circ} \mathrm{C}$ for $1 \mathrm{~min}$ and $30 \mathrm{sec}$. The other set of primers are located in the neo gene; their sequences are: 5'-CAAGATGGGATTG- 
Qiu et al.

CACGCAG-3' and 5'-CATCCTGATCGACAAGAC-3'. The PCR conditions for these primers are $95^{\circ} \mathrm{C}$ for 2 min, 35 cycles of $95^{\circ} \mathrm{C}$ for $1 \mathrm{~min}, 61^{\circ} \mathrm{C}$ for $1 \mathrm{~min}$, and $72^{\circ} \mathrm{C}$ for $1 \mathrm{~min}$.

\section{Skeletal analysis}

Bone and cartilage preparations were performed as described by (McLeod 1980).

\section{Northern analysis and in situ RNA hybridization}

Northern analysis was performed using standard methods (Sambrook et al. 1989|. In situ hybridization was performed as described in Bulfone et al. (1993b). Dlx-2 expression was studied using three different probes: Probe 1 encodes $\sim 0.8 \mathrm{~kb}$ from the undeleted region in the $5^{\prime}$ end of the cDNA (probe 1 in Fig. 1A); probe $2(0.75 \mathrm{~kb})$ encodes a region from the $3^{\prime}$ end of the cDNA that is deleted in the mutants (probe 2 in Fig. $1 \mathrm{~A}$ ); probe 3 encodes the full-length $D l x-2$ cDNA. The $D l_{x}-1$ probe was generated from a full-length $(2.8 \mathrm{~kb})$ Dlx-1 cDNA clone (A. Bulfone, $\mathrm{Xu}$ and J.L.R. Rubenstein, unpubl.). The $D l x-5$ probe was produced from a 1-kb cDNA containing its homeo box and 3' sequences (J. Liu and J.L.R. Rubenstein, unpubl.). The $E m x-1$ probe was transcribed from a $0.9-\mathrm{kb}$ cDNA clone containing its homeo box region and the 3 '-coding sequence (M. Qiu and J.L.R. Rubenstein, unpubl.). The $N k x-2.1$ probe was generated from a 2.6-kb cDNA clone (D. Hartigan and J.L.R. Rubenstein, unpubl.).

\section{Immunohistochemistry}

Immunohistochemistry was carried out as described by Uchida et al. (1994). E10.5 embryos from heterozygous intercrosses were isolated and immunostained with an anti- $\alpha \mathrm{N}$-catenin (NCAT-2) monoclonal antibody, which was kindly provided by Dr. M. Takeichi (University of Kyoto, Japan).

\section{Acknowledgments}

This work was supported by a National Institutes of Health (NIH) postdoc fellowship to M.S.Q. and grants to J.L.R.R. (March of Dimes, National Alliance for Research on Schizophrenia and Depression (NARSAD), the John Merck Fund, Pfizer Pharmaceuticals, and National Institute of Mental Health RO1 MH49428-01 and K02 MH01046-01) and to R.A.P. (NIH grant HD26732 and U.S. Department of Energy/OHER contract no. DE-ACO3-76-SF01012) and to S.M. (NATO and FIC NIH 1 F05 TW05100). We thank Dr. Teresa McGuinniess and Danwen Xu for providing the Dlx-2 genomic clones isolated from 129J library (from Anton Berns), Dr. M Takeichi for the anti- $\alpha$ N-catenin (NCAT-2) monoclonal antibody, Dr. Jenkuei Liu for the DlX-5 probe, and Dennis Hartigan for the $N k x-2.1$ probe, Stewart Anderson for his studies on the histology of the mutant olfactory bulbs, and Sandy Chen for technical assistance. We also thank the following people for commenting on the manuscript: Robert Presley, Andrew Lumsden, Edward Rubenstein, Olivier Rieppel, and the members of the Rubenstein laboratory. Finally, we thank Andrew Echt for helping to prepare the manuscript.

The publication costs of this article were defrayed in part by payment of page charges. This article must therefore be hereby marked "advertisement" in accordance with 18 USC section 1734 solely to indicate this fact.

\section{References}

Akimenko, M.A., M. Ekker, J. Wegner, W. Lin, and M. Westerfield. 1994. Combinational expression of three zebrafish genes related to Distal-Less: Part of a homeo box gene code for the head. I. Neurosci. 14: 3475-3486.

Barghusen, H.R. and J.A. Hopson. 1979. The endoskeleton: The comparative anatomy of the skull and the visceral skeleton. In Hyman's comparative certebrate anatomy, 3rd ed., pp. 265-326. The University of Chicago Press, Chicago, Il.

Baroffio, A., E. Dupin, and N.M.L. Douarin. 1991. Common precursors for neural and mesectodermal derivatives in the cephalic neural crest. Development 112: 301-305.

Beauchemin, M. and P. Savard. 1992. Two distal-less related homeo box-containing genes expressed in regeneration blastemas of the newt. Dev. Bio. 154: 55-65.

Bronner-Fraser, M. and S. Fraser. 1989. Developmental potential of avian trunk neural crest cells in situ. Neuron 3: 755-766.

Bulfone, A., H.J. Kim, L. Puelles, M.H. Porteus, J.F. Grippo, and J.L.R. Rubenstein. 1993a. The mouse Dlx-2 (Tes-1) gene is expressed in spatially restricted domains of the forebrain, face, and limbs in midgestation mouse embryos. Mech. Dev. 40: $129-140$.

Bulfone, A., L. Puelles, M.H. Porteus, M.A. Frohman, G.R. Martin, and J.L.R. Rubenstein. 1993b. Spatially restricted expression of Dlx-1, Dlx-2(Tes-1), Gbx-2, and Wnt-3 in the embryonic day 12.5 mouse forebrain defines potential transverse and longitudinal segmental boundaries. I. Neurosci. 13: $3155-3172$.

Carpenter, E.M., J.M. Goddard, O. Chisaka, N.R. Manley, and M.R. Capecchi. 1993. Loss of Hox-a1 (Hox 1.6) function results in the reorganization of the murine hindrbrain. Development 118: 1063-1075.

Chisaka, O. and M.R. Capecchi. 1991. Regionally restricted developmental defects resulting from targeted disruption of the mouse homeo box gene hox1.5. Nature 350: 473-479.

Chisaka, O., T.S. Musci, and M.R. Capecchi. 1992. Developmental defects of the ear, cranial nerves, and hindbrain resulting from targeted disruption of the mouse homeo box gene Hox-1.6. Nature 355: 516-520.

Cohen, S.M., G. Brönner, F. Küttner, G. Jürgens, and H. Jäckle. 1989. Distal-less encodes a homeo domain protein required for limb development in Drosophila. Nature 338: 432-434.

Couly, G.F., P.M. Coltey, and N.M.L. Douarin. 1993. The triple origin of skull in higher vertebrates: A study in quail-chick chimeras. Development 117: 409-429.

Cseriesi, P., B. Lilly, L. Bryson, Y. Wang, D.A. Sassoon, and E.N. Olson. 1992. MHox: A mesodermally restricted homeodomain protein that binds an essential site in a muscle creatine kinase enhancer. Development 115: 1089-1101.

Davis, C.A. and A.L. Joyner. 1988. Expression patterns of the homeo box-containing genes En-1 and En-2 and the protooncogene int-1 diverge during mouse development. Genes \& Dev. 2: 1736-1744.

de Beer, G.R. 1985. The Development of the vertebrate skull. The University of Chicago Press, Chicago, IL.

Dirkson, M. L., P. Mathers, and M. Jamrich. 1993. Expression of a Xenopus Distal-less homeo box gene involved in forebrain and cranio-facial development. Mech. Dev. 41: 121-128.

Dollé, P., T. Lufkin, R. Krumlauf, M. Mark, D. Duboule, and P. Chambon. 1993. Local alterations of Krox-20 and Hox gene expression in the hindbrain suggest lack of rhombomeres 4 and 5 in homozygote null Hoxa-1 (Hox-1.6) mutant embryos. Proc. Natl. Acad. Sci. 90: 7666-7670.

Farbman, A.I. 1991. Developmental neurobiology of the olfactory system. In Smell and taste in health and disease (ed. 
T.V. Getchell), pp. 19-33. Raven Press, New York.

Feduccio, A. and E. McCrady. 1991. The skeleton. In Torrey's morphogenesis of the vertebrates, 5th ed., pp. 201-251. Wiley, New York.

Fourie, S. 1974. The cranial morphology of Thrinaxodon liorhinus seeley. Ann. S. Afr. Mus. 65: 337-400.

Gaunt, S.J., M. Blum, and E.M.D. Robertis. 1993. Expression of the mouse goosecoid gene during mid-embryogenesis may mark mesenchymal lineages in the developing head, limbs, and body wall. Development 117: 769-778.

Gendron-Maguire, M., M. Mallo, M. Zhang, and T. Gridley. 1993. Hoxa-2 mutant mice exhibit homeotic transformation of skeletal elements derived from cranial neural crest. Cell 75: 1317-1331.

Johnson, R.S., M. Sheng, M.E. Greenberg, R.D. Kolodner, V.E. Papaioannou, and B.M. Spiegelman. 1989. Targeting of nonexpressed genes in embryonic stem cells via homologous recombination. Science 245: 1234-1236.

Joyner, A.L. 1994. Gene targeting. Oxford University Press, New York.

Joyner, A.L., K. Herrup, B.A. Auerbach, C.A. Davis, and J. Rossant. 1991. Subtle cerebellar phenotype in mice homozygous for a targeted deletion of the En-2 homeo box. Science 251: 1239-1243.

Krumlauf, R. 1993. Hox genes and pattern formation in the branchial region of the vertebrate head. Trends Genet. 9: 106-112.

Langille, R.M. and B.K. Hall. 1993. Pattern formation and the neural crest. In The skull, Vol. 1 (ed. J. Hanken and B.K. Hall), pp. 77-111. The University of Chicago Press, Chicago, Il.

LeDouarin, N.M., C. Ziller, and G.F. Couly. 1993. Patterning of neural crest derivatives in the avian embryo in vivo and in vitro studies. Dev. Bio. 159: 24-49.

Lufkin, T., A. Dierich, M. LeMeur, M. Mark, and P. Chambon. 1991. Disruption of the Hox-1.6 homeo box gene results in defects in a region corresponding to its rostral domain of expression. Cell 66: 1105-1119.

Lumsden, A. and R. Keynes. 1989. Segmental patterns of neuronal development in the chick hindbrain. Nature 33: 424428.

Lumsden, A., N. Sprawson, and A. Graham. 1991. Segmental origin and migration of neural crest cells in the hindbrain region of the chick embryo. Development 113: 1281-1291.

Luskin, M.B. 1993. Restricted proliferation and migration of postnatally generated neurons derived from the forebrain subventricular zone. Neuron 11: 173-189.

MacKenzie, A., M.W.J. Ferguson, and P.T. Sharpe. 1991. Hox-7 expression during murine craniofacial development. Development 113: 601-611.

Martin, J., A. Bradley, and E. Olson. 1995. The paired-like homeo box gene MHox is required for early events of skeletogenesis in multiple lineages. Genes \& Dev. 9: 1237-1249.

Matsuo, T., N. Osumi-Yamashita, S. Noji, H. Ohuchi, E. Koyama, F. Myokai, N. Matsuo, S. Taniguchi, H. Doi, S. Iseki, Y. Ninomiya, M. Fujiwara, T. Watanabe, and K. Eto. 1993. A mutation in the Pax-6 gene in rat small eye is associated with impaired migration of midbrain crest cells. $\mathrm{Na}$ ture Genet. 3: 299-304.

McLeod, M.J. 1980. Differential staining of cartilage and bone in whole mouse fetuses by alcian blue and alizarin red s. Teratology 22: 299--301.

Mina, M., J. Gluhak, W. Upholt, E. Kollar, and B. Rogers. 1995. Experimental analysis of Msx-1 and Msx-2 gene expression during chick mandibular morphogenesis. Dev. Dynamics 202: 195-214.
Noden, D.M. 1983. The role of the neural crest in patterning of avian cranial skeletal, connective, and muscle tissues. Dev. Biol. 96: 144-165.

- 1988. Interactions and fates of avian craniofacial mesenchyme. Development Suppl. 121-140.

Novacek, M.J. 1993. Patterns of diversity in the mammalian skull. In The skull, Vol. 2 (ed. J.H. Hanken and B.K. Hall), pp. 438-546. The University of Chicago Press, Chicago, Il.

Papalopulu, N. and C. Kintner. 1993. Xenopus Distal-less related homeo box genes are expressed in the developing forebrain and are induced by planar signals. Development 117: 961-975.

Porteus, M.H., A. Bulfone, R.D. Ciaranello, and J.L.R. Rubenstein. 1991. Isolation and characterization of a novel cDNA clone encoding a homeo domain that is developmentally regulated in the ventral forebrain. Neuron 7: 221-229.

Presley, R. 1981. Alisphenoid equivalents in placentals, marsupials, monotremes and fossils. Nature 294: 668-670.

Presley, R. and F.L.D. Steel. 1976. On the homology of the alisphenoid. J. Anat. 121: 441-459.

Price, M., M. Lemaistre, M. Pischetola, R.D. Lauro, and D. Duboule. 1991. A mouse gene related to Distal-less shows a restricted expression in the developing forebrain. Nature 351: 748-751.

Price, M., D. Lazzaro, T. Pohl, M.G. Mattei, U. Rüther, J.C. Olivo, D. Duboule, and R.D. Lauro. 1992. Regional expression of the homeo box gene $N k x-2.2$ in the developing mammalian forebrain. Neuron 8: 241-255.

Puelles, L. and J.L.R. Rubenstein. 1993. Expression patterns of homeo box and other putative regulatory genes in the embryonic mouse forebrain suggest a neuromeric organization. Trends Neurosci. 16: 472-479.

Rieppel, O. 1993. Patterns of diversity in the reptilian skull. In The skull, Vol. 2 (ed. J. Hanken and B.K. Hall), pp. 344-390. The University of Chicago Press, Chicago, Il.

Rijii, F.M., M. Mark, S. Lakkaraju, A. Dierich, P. Dollé, and P. Chambon. 1993. A homeotic transformation is generated in the rostral branchial region of the head by disruption of hoxa-2, which acts as a selector gene. Cell 75: 1333-1349.

Robinson, G.W. and K.A. Mahon. 1994. Differrential and overlapping expression domains of $D l x-2$ and $D l x-3$ suggest distinct roles for Distal-less homeo box genes in craniofacial development. Mech. Dev. 48: 199-215.

Robinson, G.W., S. Wray, and K.A. Mahon. 1991. Spatially restricted expression of a member of a new family of murine Distal-less homeo box genes in the developing forebrain. New Biol. 3: 1183-1194.

Rubenstein, J.L.R. and L. Puelles. 1994. Homeobox gene expression during development of the vertebrate brain. In Current Topics in developmental biology, Vol. 29 (ed. R.A. Pederson), pp. 1-63. Academic Press, San Diego, Ca.

Rubenstein, J.L.R., S. Martinez, K. Shimamura, and L. Puelles. 1994. The embryonic vertebrate forebrain: The prosomeric model. Science 266: 578-580.

Salinas, P.C. and R. Nusse. 1992. Regional expression of the Wnt-3 gene in the developing mouse forebrain in relationship to diencephalic neuromeres. Mech. Dev. 39: 151-160.

Sambrook, J., E.F. Fritsch, and T Maniatis. 1989. Molecular cloning, 2nd ed. Cold Spring Harbor Laboratory Press, Cold Spring Harbor, New York.

Satokata, I. and R. Maas. 1994. Msx1 deficient mice exhibit cleft palate and abnormalities of craniofacial and tooth development. Nature Genet. 6: 348-356.

Sechrist, J., G.N. Serbedzija, T. Scherson, S.E. Fraser, and M. Bronner-Fraser. 1993. Segmental migration of the hindbrain neural crest does not arise from its segmental generation. 


\section{Qiu et al.}

Development 118: 691-703.

Simeone, A., D. Acampora, M. Gulisano, A. Stornaiuolo, and E. Boncinelli. 1992. Nested expression domains of four homeobox genes in developing rostral brain. Nature 358: 687690.

Simeone, A., D. Acampora, M. Pannese, M. D'Esposito, A. Stornaiuolo, M. Gulisano, A. Mallamaci, K. Kastury, T. Druck, K. Huebner, and E. Boncinelli. 1994. Cloning and characterization of two members of the vertebrate Dlx gene family. Proc. Natl. Acad. Sci. 91: 2250-2254.

Stern, C.D., K.F. Jaques, T.M. Lim, S.E. Fraser, and R.J. Keynes. 1991. Segmental lineage restrictions in the chick embryo spinal cord depend on the adjacent somites. Development 113: 239-244.

Thomas, K.R. and M.R. Capecchi. 1987. Site-directed mutagenesis by gene targeting in mouse embryo-derived stem cells. Cell 51: 503-512.

Tybulewicz, V.L.J., C.E. Crawford, P.K. Jackson, R.T. Bronson, and R.C. Mulligan. 1991. Neonatal lethality and lymphopenia in mice with a homozygous disruption of the c- $a b l$ protooncogene. Cell 65: 1153-1163.

Uchida, N., K. Shimamura, S. Miyatani, N.G. Copeland, D.J. Gilbert, N.A. Jenkins, and M. Takeichi. 1994. Mouse n-catenin: Two isoforms, specific expression in the nervous system, and chromosomal localization of the gene. Dev. Biol. 163: 78-85.

Wurst, W., A.B. Auerbach, and A.L. Joyner. 1994. Multiple developmental defects in Engrailed-1 mutant mice: and early midhindbrain deletion and patterning defects in forelimbs and sternum. Development 120: 2065-2075.

Zhao, G.Q., S. Zhao, X. Zhou, H. Eberspaecher, M. Solursh, and B. de Crombrugghe. 1994. rDlx, an novel distal-less-like homeoprotein is expressed in developing cartilages and discrete neuronal tissues. Dev. Biol. 164: 37-51. 


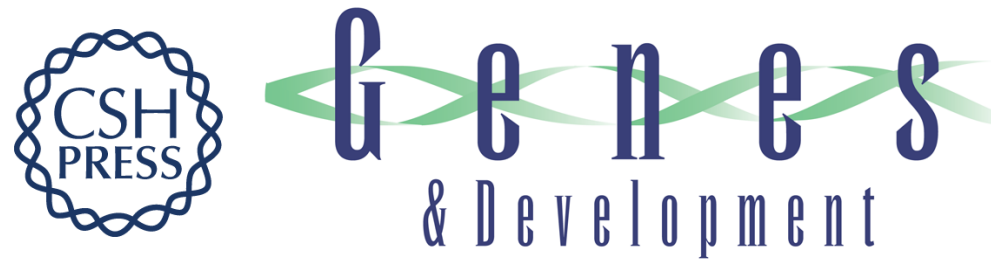

\section{Null mutation of Dlx-2 results in abnormal morphogenesis of proximal first and second branchial arch derivatives and abnormal differentiation in the forebrain.}

M Qiu, A Bulfone, S Martinez, et al.

Genes Dev. 1995, 9:

Access the most recent version at doi:10.1101/gad.9.20.2523

References This article cites 54 articles, 19 of which can be accessed free at:

http://genesdev.cshlp.org/content/9/20/2523.full.html\#ref-list-1

License

Email Alerting

Service

Receive free email alerts when new articles cite this article - sign up in the box at the top right corner of the article or click here.

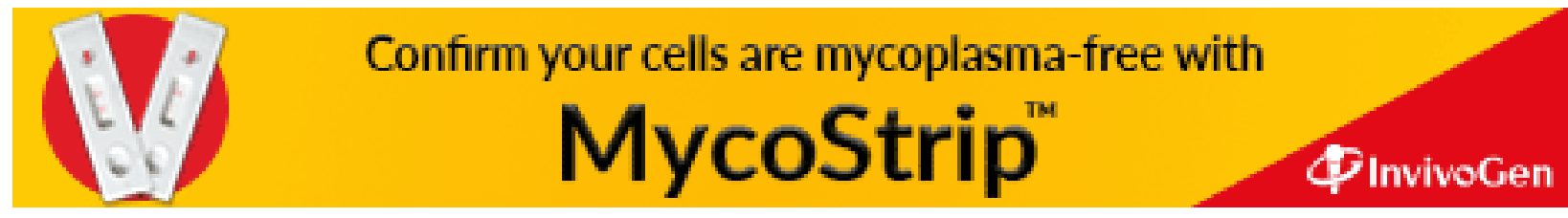

